\title{
LA TÉSERA CELTIBÉRICA DE SASAMÓN (K.14.1)
}

FRANCISCO J. RUBIO ORECILLA

Universidad de Saarbrücken

En este trabajo analizo la tésera celtibérica de Sasamón (K.14.1). La inscripción es un documento de hospitalidad bilateral entre IroreKiios, calificado de monituuKoos, y Nemaios. Es verosímil que monituuKoos, base de derivación del epíteto de las Matres Monitucinae, sea un adjetivo étnico; no obstante también podría explicarse como un apelativo compuesto de los elementos *moni'tutela' y *tuk(o)- 'descendencia, hijos'. En la segunda cara de la inscripción aparece aleTuures, que podría ser un nominativo plural, en concordancia con IroreKiios y Nemaios; pero un tema aleTur- presenta tantos problemas formales que hay que buscar otra solución. AleTuures podría ser también un nominativo singular, en concordancia con Nemaios, pero su identificación como étnico $\left(i^{*}\right.$ alleto-rēgs $=$ allot-rīg-es $\left.?\right)$ es más que problemática. Finalmente, podría ser un nombre de persona (aunque sin paralelos en el repertorio onomástico hispanocéltico), y entonces el pacto habría tenido dos partes, por un lado el individuo llamado aleTuures, sorprendentemente sin más identificación, y por otro IroreKiios el *Monitucense junto con Nemaios, cuya relación mutua vendría a ser en ese caso más bien obscura. También se proponen o discuten etimologías para los topónimos Munébrega y Monesma (de *mono- 'montaña'), étnicos como autrigones, allotriges y palabras celtibéricas como sToTeroi.

Palabras clave: lingüística céltica, hispano-céltico, celtibérico, hospitalidad, téseras, etimología.
In this paper the Celtiberian tessera K.14.1 from Sasamon is analyzed. The inscription is a twofold hospitium document between IroreKiios, qualificated of monituuKoos, and Nemaios. Likely monituuKoos, which we find as a derivation basis of the epitheton of the Matres Monitucinae, is an ethnic adjective; nevertheless it could also be explained as an appelative containing *moni- 'legal protection' and *tuk(o)- 'descendance, sons'. On the other side of the inscription the word aleTuures should be a nominative plural, agreeing both IroreKiios and Nemaios; but there are so many formal problems concerning such a stem *aleTur-, that we must seek for another solution. AleTuures could also be a nominative singular, agreeing with Nemaios; but its identification as an ethnic designation (*alleto-rēgs = allot-rīg-es?) would be very problematic. Finally, it could be a personal name (allthough without parallels in the hispanoceltic onomastics), and then the pact would have two participants, the surprisingly unidentified individual aleTuures on one side, and on the other IroreKiios the *Monitucean and Nemaios, whose mutual relation would thereupon be misterious. Etymologies for the toponyms Munébrega and Monesma (both from *mono- 'mountain'), ethnic names as autrigones, allotriges or Celtiberian words as sToTeroi are here propossed or discussed.

Keywords: Celtic linguistics, Hispano-Celtic, Celtiberian, hospitality, tessera, etymology

1. La tessera hospitalis K.14.1, llamada por su procedencia de Sasamón, es una pieza de bronce en forma de silueta de cuadrúpedo, escrita por las dos caras, con repetición de la vocal correspondiente a cada silabograma, 
algo que se produce en otras inscripciones procedentes de Burgos (K.13.1 y 2, lápidas de Clunia; K.24.1, tésera de Belorado) y en una de Numancia (K.9.2, sobre cerámica). El texto (J. Untermann, $M L H$ IV, pp. 687-88) es el siguiente:

\section{K.14.1(A) iroreKiios moniTuuKoos nemaios}

\section{(B) aleTuures}

Por lo general, se ha interpretado la última palabra como un compuesto con -res <*rêg-s 'rey' (p. ej., J. De Hoz 1986, pp. 71, 77; W. Meid 1993, p. $71)$, destino que sufre al parecer toda palabra celtibérica que acaba en -res ${ }^{1}$. En principio, parece más económico entender, con Lejeune $(1955$, p. 84) y Untermann (MLH IV, p. 405) entre otros, que aleTuures es un nominativo plural en aposición a las palabras de la otra cara, iroreKiios, moniTuuKoos y nemaios, en apariencia tres nominativos singulares; al menos el último es claramente un antropónimo ( $(7)$. No obstante, es necesario examinar en detalle otras posibilidades, ya que no aparecen fórmulas onomásticas claras y con ese análisis (tres antropónimos en nominativo, sin filiación y en asíndeton, calificados por el mismo adjetivo) no queda clara la función de los diversos individuos nombrados en la tésera; ésa es una estructura sin paralelos en la tipología de los documentos celtibéricos de hospitalidad. Y además, también es la única tésera celtibérica plana escrita por las dos caras, hecho que pone de manifiesto de modo elocuente la singularidad de esta inscripción: sea cual sea su explicación, estará fuera de lo usual; es algo a lo que hay que enfrentarse sin obviar ninguna de las posibles explicaciones, por fatigoso que resulte.

2. Como posible paralelo de una tésera escrita por las dos caras tenemos la inscripción latina de Herrera de Pisuerga (Valladolid), un documento de hospitalidad en el que la ciuitas Mag(g)auiensium inscribe su versión del pacto en una cara y en el reverso hace lo propio el otro contrayente, un particular llamado Amparamus Nemaioq[um] - casualmente, Nemaioq[um] es un NF derivado del NP nemaios de nuestra tésera -; incluso se detectan diferencias gráficas entre las dos caras, v. F. Beltrán, 2001, pp. 45-46. También la estructura de la tésera de Herrera de Pisuerga es única; ¿sería ése un modelo aplicable a K.14.1? Desde luego, sólo lo sería de modo genérico: en caso de que al menos alguna de las cuatro palabras de K.14.1 se refiriese a un ciudad o etnia, esta inscripción podría entenderse como el pacto entre los individuos consignados una cara, con constancia de su origo, y el o los ale-

1 Al respecto, v. la crítica de D. Wodtko, 1999, p. 739. 
Tuures de la otra. Pero no hay diferencias gráficas entre ambas caras, en ambas se dan las mismas singularidades ( $工 \mathrm{tu}, \bigotimes e$, variantes únicas en la epigrafía celtibérica), lo cual garantiza que toda la inscripción se debe a una sola mano. Si se toma como modelo la tésera latina de Herrera de Pisuerga, necesariamente aleTuures habría de identificar a una de las partes: sólo podría ser o un étnico, o un antropónimo.

3. En cierta medida, los problemas de K.14.1 recuerdan a los de K.18.3, en la cual también aparecen formas en -es de interpretación conflictiva, especialmente el NP PunTunes (*Bundūn-, cf. NP PunTalos K.0.7, NF BVNDALICO, CIL II 2785, Clunia). Pero K.18.3 es una tésera poliédrica, formada por cuatro "dientes" o, por emplear el término de Untermann, "dedos" ortoédricos, destinados a encajar en otra pieza simétrica, así que no cabe hablar de "dos caras", como tampoco es el caso en otras téseras poliédricas. El texto aparece en las caras contiguas de tres de los "dedos", y aunque posiblemente en cada cara se hace referencia a un partícipe del pacto distinto (ueniaKum vs. PunTunes), no se puede descartar por completo que parte del texto de B (irulases o PunTunes) siga o encabece el texto de A. PunTunes puede ser un genitivo singular de un antropónimo en $-\bar{u} n$, con una desinencia $*_{-}-\bar{s}<*$-eis tomada de los temas en $-i-$, monoptongada como en sTenioTes K.17.1, STENIONTE ... GENTE K.11.1. O puede ser el nominativo plural de un étnico similar a Berones, Vascones, Pelendones, Lusones, etc., lo cual proporciona una morfología menos problemática; precisamente Vascones y Berones son las dos etnias próximas a Vareia, muy cercana a Viana, de donde procede K.18.3. El problema para ver un nom. pl. en PunTunes es que se suele identificar PunT- con el tema antroponímico presente en PunTalos, $B V N D A L I C O(m)$ que acabamos de citar. Ciertamente, hay nombres de ciudad que son temas en $-\bar{u} n$, v.gr. Purzau $\sim$ Bursao(nenses), Turiazu $\sim$ Turiasso; así, si PunTunes fuese un étnico nom. pl., hay que presuponer que un NL *Buntū $\sim$ *Bundū se pudiese emplear, en pl. y sin sufijos, como étnico; así, frente al modelo de derivación usual NL oilaunu, -ez $\rightarrow$ etn. oilaun-ikum (A.56), el caso de *Bund $\rightarrow$ $\rightarrow$ PunTunes sería comparable con el del NL "A$\lambda \alpha \beta \alpha$ (Ptol. II, 6, 58N) $\rightarrow$ etn. alaPoi (K.0.7), nom. pl. sin sufijo (= Alabensis, CIL II 4200, Tarragona) ${ }^{2}$. En K.18.3 irulases (o iteulases) puede estar concertado con PunTunes, como gen. sg. de un tema en -i-, o como nomina-

\footnotetext{
2 El inicio de K.0.7, donde aparece el mencionado alaPoi, podría entenderse así como una oración nominal con omisión del verbo copulativo: ]kuPos (var. lect. ]rPos): oPoi : KorTono : alaPoi "para X (dat. pl.): (que sean) oboi de Kortono los Alabenses".
} 
tivo plural, pero la forma en sí es muy obscura.

4. Así pues, si consideramos la posibilidad de que K.14.1 sea una tésera bilateral y que los integrantes del pacto se hayan consignado cada uno en una cara, como en la tésera de Herrera de Pisuerga, aleTuures se referirá a una parte, iroreKiios moniTuuKoos nemaios a la otra. Formalmente, aleTuures puede ser un nominativo plural, y designaría así a uno de los grupos que emite la tésera; pero esto tropieza con el hecho de que en el corpus celtibérico - dejando al margen la fórmula mayoritaria X-Ka Kar (uel X-ina Kar), donde $\mathrm{X}$ es un nombre de ciudad -, predominan en esa función los NNP de individuo en genitivo o nominativo singular, o los genitivos de plural de adjetivos étnicos o gentilicios en $-\mathrm{ko-}^{3}$; nunca los nominativos plurales (los únicos ejemplos en un documento de hospitalidad serían, llegado el caso, PunTunes irulases y oboi ... alaPoi ${ }^{4}$ comentados en $\S 3$ ). Por tanto, no se puede excluir que aleTuures sea el nominativo singular de un tema en dental o gutural (-es $<*_{\text {-ets, }} *_{-}$exs $)$, o un genitivo singular ${ }^{5}$ en $-\bar{e} s<*_{\text {-eis }}$ de un tema en $-i-0$, con menor verosimilitud, en consonante: entonces estamos ante el pacto de un individuo con iroreKiios moniTuuKoos nemaios, secuencia que en absoluto resulta inequívoca.

5. La hipótesis de que iroreKiios, moniTuuKoos y nemaios sean los nombres propios de tres individuos distintos parece poco plausible, ya que los pactos de hospitalidad se establecen entre dos particulares, o entre una comunidad y un individuo (y sus descendientes, como en la tésera de Herrera de Pisuerga), o entre dos comunidades (ciudades, etnias, familias; v.gr.

3 Genitivos plurales de adjetivo en -ko-: K.0.13 KorToniKum : TuiniKuKuei : Kar (var. lect. TuiniKuKuei : KorToniKum : Kar), K.18.1 PerKuaKum : saKas (< ¿NL *Bergua?), K.18.3 KuPoKariam : ueniaKum (< ¿NL Venia? Cf. Vennenses Plin., N.H. III, 26); en K.0.6 aTuliKum es la designación de un grupo familiar como partícipe de un pacto de hospitadad, cfr. el NP Atullus como base de derivación. Algo similar puede estar presente en K.14.2 TRIDONIECV: CARA|CA: DESSVAEONA | NEMAIOSQ, si se admite una lectura TRIDONIECV $(m)$, como gen. pl. de un NF derivado de la base onomástica *Trito-(no-); en cambio para Untermann, 1995, p. 203, «Tridoniecu nombra ... a los habitantes de la ciudad que participan en el hospitium»: el paralelo se establece entonces entre K.0.13 KorToniKum (..) Kar y TRIDONIECV(m) CARA $\mid$ CA.

4 Pero el bronce de Medinaceli (K.0.7) donde aparecen oPoi ... alaPoi (v. nota 2) es una tabula, no una tessera.

5 Hay buenos ejemplos de genitivo singular, tanto en téseras unilaterales: reTuKeno : uisal|iKum (K.0.9), lenTioKo : slaniaz (Villar, 1999), como en bilaterales: areKoratiKa Kar | seKilaKo : amiKum...( K.0.11). 
CAAR $\cdot$ ICVRBICA $\mid$ SALVANTICA $\mid$ QVE) ${ }^{6}$, no entre una comunidad (aleTuures como nominativo plural) o un individuo (aleTuures como singular) y tres individuos sin filiación. Existen téseras itálicas de fecha republicana entre particulares, un ciudadano romano y un extranjero, por las que se establece un pacto en pie de igualdad, extensivo a los descendientes de las dos partes (cf. Beltrán, 2001, pp. 37-38); algunas de las téseras latinas de Hispania «verosímilmente ... sancionan acuerdos interindividuales entre ciudadanos romanos y peregrinos» (Beltrán, 1.c., p. 41). Como es sabido, en las téseras celtibéricas suele aparecer una designación local, por lo general un adjetivo formado a partir del nombre del lugar o etnia que emite el documento de hospitalidad, o en su defecto, se señala la origo del titular del documento, al que en pocos casos se le designa sin un NF. Evidentemente, únicamente en las téseras celtibéricas unitaterales en las que sólo aparece un nombre de individuo, con o sin expresión de origo (K.0.2, K.0.9; lenTioKo slaniaz (Villar, 1999), K.24.1, ¿K.0.6, cf. nota 3, K.0.10, K.18.4?), se puede pensar que siguen el modelo itálico de pacto entre un romano y un peregrinus; pero no necesariamente en todos esos casos, ya que una buena parte de las téseras celtibéricas son documentos públicos: pueden ser el documento identificativo del particular que establece un pacto con una comunidad. En las téseras bilaterales, como K.0.11, se menciona claramente a un individuo y una ciudad; en téseras unilaterales esa expresión de la origo puede aparecer en ablativo, acompañando al nombre del posesor del documento de hospitalidad (luPos : alizo|Kum : aualo : Ke |KonTePiaz|PelaisKaz, K.0.2; lentioKo slaniaz, F. Villar, 1999; quizá K.24.1 seKeeios : saileTiiKoo : meTaama, si se admite la pérdida de $*_{-} \circlearrowright$ final en *metamād), o puede expresarse mediante un adjetivo, como sucede al parecer en DVREITA TARVODVRE $\angle S C A>$ LIGORIQ[um], con la lectura TARVODVRE $\angle S C A>$ como adjetivo derivado de un topónimo *Tarvo-durom ${ }^{7}$, y acaso también en la tésera de Ubierna, posiblemente bilateral AMBATO $\cdot \operatorname{VIROVARCO}(\ldots)^{8}$. También puede incluirse el NP de un magistrado, como en la tésera latina de Las Merchanas (tesera Cauriensis magistratu Turi), o en la de Arecorata (K.0.11, PisTiros : lasTiKo: ueizos), en cuyo caso se señala el cargo (magistratu, ueizos). En ausencia de fórmulas onomásticas claras, habrá que suponer que en la tésera de Sasamón al menos

\footnotetext{
6 Tésera de la Mesa del Almendro, J. Remesal Rodríguez, 1999.

7 F. Villar y J. Untermann, 1999, pp. 727-731; para la lectura TARVODVRE $\angle S C A>$ (SCA aparece en la línea superior, sobre las letras $R E$ de $-D V R E)$, v. p. 730.

$8 \quad \mathrm{M}^{\mathrm{a}}$ A. Castellano y H. Jimeno, 1999, pp. 359-361.
} 
alguna de las palabras indica la origo de una de las partes, o, dado el caso, que se nombra a un magistrado con un término todavía no documentado.

6. Así, una opción es suponer que iroreKiios y monituuKoos fuesen adjetivos o substantivos, o un substantivo y un adjetivo, en aposición al nombre propio nemaios; pero en ese caso habrá que explicar porqué aparecen antepuestos y no postpuestos, como es usual en los epítetos étnicos o en la designación de magistraturas (K.1.1, b.1 luPos: KounesiKum: melmunos: P i n t is; K.0.11, PisTiros: lasTiKo: u e i z o s ); ya hemos visto que en la tésera latina de Las Merchanas basta con señalar el centro emisor (Cauriensis) y el nombre de un magistrado. En principio, al menos moniTuuKoos parece un posible candidato como designación étnica, v. infra §§ 7-10. Entonces, dos individuos, uno llamado iroreKiios, calificado de moniTuuKoos (¿étnico? ¿designación de una magistratura?), y un nemaios, sin calificativo alguno, establecen un pacto de hospitalidad con el o los aleTuures. Ahora bien, si se prescinde del paralelo con la tésera latina de Herrera de Pisuerga, el hecho de que aleTuures aparezca en la otra cara sólo implicará que hay que leer aleTuures a continuación de iroreKiios moniTuuKoos nemaios; este desplazamiento de uno de los términos a la segunda cara puede ser casual, o intencionado, en caso de que aleTuures se refiera a todos los individuos enumerados en la otra cara. Así las cosas, las opciones son las siguientes:

a) K.14.1 es una tésera bilateral entre un individuo llamado iroreKiios, calificado de moniTuuKoos (¿étnico?), y otro, nemaios, calificado de aleTuures; ambos partícipes se mencionan en asíndeton y en nominativo singular.

b) K.14.1 es una tésera bilateral entre iroreKiios, calificado de moniTuuKoos (¿étnico?), y nemaios, sin calificar; aleTuures, en el reverso, es un nominativo plural referido a ambos partícipes del pacto.

c) Con menor verosimilitud, sólo en el caso de poderse demostrar que iroreKiios moniTuuKoos fuesen apelativos concertados con nemaios - lo que explicaría la ausencia de conjunciones -, K.14.1 sería una tésera bilateral, similar en su cara [A] a la tésera de las Merchanas (§ 5): iroreKiios moniTuuKoos nemaios habría de ser "el magistrado monitucense (llamado) Nemaios"; aleTuures daría expresión al o a los beneficiarios. Pero en la tésera de las Merchanas se expresa claramente que estamos ante un documento de hospitalidad (teser a Cauriensis, equivalente directo de la fórmula celtibérica $\mathrm{X}-\mathrm{Ka}$ (KorTiKa) Kar) y en cambio iroreKiios no tiene relación con el léxico celtibérico de hospitalidad (Kar = CARACA o Karuo, KorTiKa, ueizo- (ueizia-), Kenis : esKe(i)nis...)

7. El elemento más claro de la inscripción es el NP nemaios, que signifi- 
cativamente aparece también en otra tésera procedente del mismo lugar, en alfabeto latino, NEMAIOSQ (K.14.2 $)^{9}$ y como base de derivación del NF Nemaioq $[u m]$ de la tésera de Herrera de Pisuerga ${ }^{10}$, v. Albertos 1987, p. 177. El otro segmento con una correspondencia clara es moniTuuKoos, que se identifica ${ }^{11}$ con un epíteto de las Matres en una inscripción de Salas de los Infantes (Burgos): MATRIBVS MONITVCINIS. M ${ }^{\mathrm{a}}$ Lourdes Albertos (1987, p. 177) entendió que moniTuuKoos era un cognomen de tipo gentilicio, y las Matres serían las protectoras de esa gentilidad. Pero como señala Untermann (MLH IV, p. 688), si el epíteto de las dioses deriva de *monituko-, entonces *monituko- ha de ser más bien un étnico; entre las advocaciones de las Matres no se encuentran epítetos derivados de antropónimos (§ 13). El étnico caracterizaría a iroreKiios mediante un nominativo singular, no con el genitivo plural; formalmente habría que compararlo con el adjetivo PeliKios que expresa la origo en la estela de Ibiza (K.16. 1). Todo esto nos lleva, en primera instancia, a las opciones $a$ ) o $b$ ): o bien aleTuures es un étnico en nominativo singular que califica a nemaios como el probable étnico moniTuиKoos a iroreKiios, o bien nemaios aparece sin filiación ni origo, quizá porque el "extranjero" que precisaba de ulteriores calificativos era iroreKiios.

8. Hay en el corpus hispánico dos palabras que se pueden relacionar con moniTuuKoos / MONITVCINIS (v. D. Wodtko, $M L H$ V/1, p. 265): por un lado el término MONIMAM, que aparece en las dos páteras de Tiermes:

\section{K.11.1 STENIONTE DOCILICO AN.GENTE.MONIMAM \\ K.11.2 COVGIO VISCI|CO MONIMAM}

Y en la lápida de Julióbriga (Cantabria):

K.26.1 ]LIC(um) VIAMI | G(entis). MONIM|AM ${ }^{12}$

\footnotetext{
9 Dejando al margen el problema de la lectura, NEMAIOSQ (= Nemaios-que o Nemaiosq[um]) o NEMAIOSO.

10 Por lo demás, la base *nem- no es desconocida en la onomástica personal céltica, cf. Holder II, col. 698 y ss., Nemaloni, Nemasius, Nemonius, etn. nemetes; irl. ant. Neman (Nemanus) y Nemain, Nemn-(u)all, brit. Nemiaus o †Nemianus...Y el sufijo -aio- es usual en la antroponimia hispanocelta.

11 J. Untermann, MLH IV, p. 688; C. Jordán, 1998, p. 152.

12 Restitución según J. Untermann, MLH IV, p. 716. El genitivo en -i VIAMI $\mid$ G(entis) ('hijo de Viamus') es problemático: o se admite la intrusión de un genitivo latino en una inscripción por lo demás en lengua indígena, como hace Untermann, o se admite una forma dialectal, algo que resulta arriesgado, v. sobre todo J. Untermann, 1995, pp. 204-205. Si es una inscripción indígena, dado que en las téseras de Tiermes MONIMAM aparece acompañado de un
} 
Y por otro lado, el teónimo lusitano MVNIDI (dat., Talaván, Cáceres, HAE 2393), como ya señalara Untermann (1990, p. 364), quien sugería un tema *monit- o *munit- (1.c. nota 89). Wodtko (1.c.) subraya la posibilidad meramente formal de que *mon-ī-tu- sea una formación postverbal, de la misma manera que MONIMAM puede analizarse también como un nombre verbal en *-mā- de una formación causativa *mon-eie-, en la línea de lo que ya propuso Gorrochategui (1990, p. 309-310) ${ }^{13}$. Ahora bien, si se parte de un tema en dental, entonces en *monit-uko- estamos ante una derivación en -uko- más bien incómoda; *-uko- $/ *-\bar{u} k o$ - suele funcionar como sufijo diminutivo o hipocorístico, cf. p. ej. galés -ug (P. Russell, 1990, p. 85), y tampoco está atestiguado con seguridad ni en celtibérico, ni en céltico hispano-occiden$\operatorname{tal}^{14}$. Una solución "elástica" sería suponer que estamos ante una variante, dialectal o expresiva, del sufijo productivo -oko-; cf. el caso muKuKaiau (K.13.2, Clunia): muKoKaiKo (K.9.1, Numancia, con sufijo occidental -aiko-), si es que efectivamente esas dos formas están en relación. Partir de un tema en -tu- permitiría explicar el vocalismo presufijal, pero implica suponer un abstracto postverbal como base de la que deriva un adjetivo en $-k o-$, antes que una base puramente onomástica o étnica. Por lo que respecta a la vinculación de moniTuuKoos, MONITVCINIS con el teónimo galaico MVNIDI (dat. sg. latino), recientemente B. Prósper (2002, p. 189) la ha vuelto

NP. en gen. (COVGIO) o en dat. (STENIONTE...GENTE), la restitución sería mas bien G(enteis $-\bar{e} s)$ o $G($ entei $\sim-\bar{e})$ : la inscripción seria "monimam para Z, de X [..]lic(um), hijo de Viamos" o “monimam para X [..]lic(um), hijo de V."; X y, dado el caso, Z estarían en la parte perdida de la inscripción.

13 Gorrochategui partía del sufijo *-mn $>*_{-}$man $>-M A M$, bien por asimilación de nasales, bien por analogía con los neutros temáticos. Ciertamente, es más fácil trabajar con un nom. sg. neutro que con un acusativo femenino, que obliga a suponer un verbo elidido (posuit, dedicauit, cf. Untermann, MLH IV, p. 716).

14 Sobre las pocas formas en -uko- atestiguadas en celtibérico, cf. Rubio Orecilla, 2001, p. 592 nota 54. En indio antiguo, báltico y eslavo se dan diversas formaciones en *-uko-, *- $\bar{k} k o$-, cuyo origen se remite sin dificultad a formantes primarios en $*_{-} u$ - (frecuentemente residuales), recaracterizados con el sufijo *-ko-: esas formaciones en $*$-uko-posteriormente tuvieron éxito como sufijos secundarios más o menos productivos de diminutivos y nombres postverbales; ninguna de ellas es heredada. Precisamente, en el epíteto teonímico hispanooccidental (matribus) SVLEIS NANTVGAICIS (Orense) se esconde un derivado en *-ko- de un tema en -u-: NANTVGAICIS, derivado en -aikk- de *nantu-ko/a-a-, v. infra $\S 13$. X. Delamarre, 2001, p. 259 aventura para el NL de la Galia Belga Aduatuca $\sim$ Atuatuca (Caes., Gall. VI 32), étn. Ad- Atuatuci (Caes., Gall. II 4.29) una etimología *ad-ụātu-kā- 'lieu où l'on prophétise', con interrogante; pero parece que la lectura correcta es Atuatuca, y el nombre es de origen germánico, como otros nombres con -uk- de la zona, v. H. Reichert, 2001, p. 490. 
a poner de relieve. Ella define MVNIDI como «tema en -id-», y propone como etimología la base *mon- 'montaña', presente en el britónico *moniio- > gal. mynydd 'montaña', y, con dental ( $\left.*_{-t-}>^{*}-t i-\right)$ en lat. mons, montis $\mathrm{y}$, según propone ella, en el epíteto de la Iūno Monèta (tradicionalmente derivado de moneo), todo lo cual en principio no es imposible. Desde el punto de vista formal la relación entre un celtibérico *monit- y un hispanocelta occidental MVNID- no es problemática, aunque tampoco concluyente. La sonorización $t->-d$ - en MVNID- sigue el modelo general en el Occidente peninsular; el ejemplo típico es precisamente la citada inscripción de Talaván, MVNIDI EBEROBRIGAE TOVDOPALANDAIGAE $<*$ touto-palantai $k \bar{a}-{ }^{15}$. Pero el vocalismo es más confuso: en principio, la $<\mathrm{V}>$ de MVNIDI sí que puede ser una grafía por *[monid-], ya que en la zona occidental se da una vacilación gráfica $\mathrm{O} \sim \mathrm{V}$, p.ej.: ALBVCELAICO / ALBOCELO, APVLVSEAECO / APOLOSEGO, COSEI, COSSVE, COHVE / CVSEI, CVSVE, CVHVE; además en la epigrafía latina peninsular la representación de $\breve{o}, \bar{o}$ o por $\langle\mathrm{V}\rangle(\dot{\zeta}=[\mathrm{o}]$ ? $)$ no es rara en sílabas abiertas pretónicas (p.ej. munimentum) ${ }^{16}$, lo que podría implicar una pronunciación *monídi. Pero tampoco la $<\mathrm{l}>$ ha de reflejar necesariamente una vocal larga: cf. p. ej. NIMMEDO (A)SEDDIACO, ${ }^{17}$ de $*_{n e m e t o-}$, donde una $*_{e}$

15 V. B. Prósper, 2002, p. 187. Por lo general se identifica *touto- en TOVDOPALANDAIGAE con *toutāa-‘pueblo, nación' (p.ej., K. H. Schmidt, 1985, p. 332, Villar 1993-1995, p. 378-379, Prósper, 1.c.); para ello hay que suponer que se produce la sustitución de $-\bar{a}$ - por la -o- en unión de compuestos, como en galo (K. H. Schmidt, 1957, p. 90). No obstante, cf. irl. ant. túath < *touto-/-a-a- 'izquierdo, al norte'. Si se acepta esa semántica para el TOVDO- de Talaván, el significado de la inscripción sería "para el o la MVNID- de la Eberóbriga (situada) al norte o a la izquierda del /la *palanto/ā-", con lo cual estaríamos ante un epíteto de la ciudad de Eberóbriga, y es indiferente ver en -brigae un genitivo latino de -brigā (substantivo) o el dativo de un adjetivo *-bri-kā-. Sólo si MVNID- fuese femenino (extremo que no garantizan las otras inscripciones donde supuestamente aparece, escasamente legibles -un ejemplo en la nota $17-)$, el adjetivo femenino *touto-palantaika $\bar{a}$ - podría concertar con él. Untermann, 1985, p. 359 señala la existencia de un MVNIDE en Chaves (Tras-os-Montes), sin epíteto, que quizá documenta un dativo indígena $<*$-ei ; Prósper, 1.c., no menciona este epígrafe.

16 A. Carnoy (1906, pp. 54-55) señala que munimentum es más frecuente en Lusitania que en otras provincias, aunque en todo caso se inclina por una contaminación de monumentum con münimentum; además, v. Carnoy, 1.c. pp. 61-62, acerca de -orC-, -oNC-, también con $<\mathrm{V}>$ por $o$ cerrada (PVNPONIVS, MVNTANVS, FVRTVNA).

17 Inscripción de Mieres (Asturias), v. F. Diego Santos, 1985, pp. 49-51; y B. Prósper, 2002 , p. 220. Debido a que todas las letras están ligadas no se puede valorar el controvertido

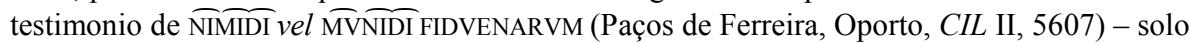
está clara la ligatura $\overparen{\mathrm{DI}}-$; también es controvertida la lectura NEME-DECO $\sim$ NEN(N)EOECO (CIL II, $2375=5552)$, cf. B. Prósper, 2002, p. 230 y para ambas inscripciones, C. Búa, 1999, 
posiblemente tónica aparece representada como $<\mathrm{l}>$, así como las variantes gráficas del teónimo VIRRORE / VERORE y de los antropónimos de la base pent-/pint-; v. además infra nota 32. En definitiva, la forma occidental no proporciona información segura sobre el vocalismo: es difícil establecer en qué casos una $<\mathrm{V}>$ representa una ${ }^{*} o$ procedente de ${ }^{*} o$, o una $*^{*} u$ antigua; una vacilación $\mathrm{O} \sim \mathrm{V}$ en sílaba átona puede implicar también un paso $* u>$ *o. Eventualmente, hay que preguntarse si MVNIDI no estará en relación con los antropónimos MVNIGALICVs (León, CIL II 5717, gen. -IGI VAD(iniensis); dat. -ICO Albertos, 1966, p. 161, Orense), MVNILla (Evora, CIL II 117), MVNNA (Lisboa, CIL 238), MVNEIA (Meixedo, Bragança); en zona celtibérica, MVNERIGIO (Calderuela, Soria, CIL II 2834) y muniKa (K.1.3, passim) y en la Beturia Céltica, MVNA, MVNE, que con toda verosimilitud presentan - $u$ antigua ${ }^{18}$; en ese caso, habría que separarlo del cib. moniTuukoos, MONITVCINIS.

9. Aun dando por buena la identificación *monit- : MVNID-, que no es más dudosa de lo usual en la Hispania Prerromana, la relación de ese *monit- ( $i * m o n i \bar{t}-<*$ mon-èt-?) con brit. *moniio - / lat. mon-t(i)- 'montaña' no carece de problemas. En la toponimia moderna de origen celta encontramos Munébrega, a unos $13 \mathrm{~km}$. de Calatayud y Monesma en el Prepirineo oscense. Dado que Munébrega aparece en documentos medievales como Monobrega, es preferibe excluir un **mūníbriga y hay que postular Munébrega $<$ *mon(u)ébrega (la segunda $o$ de la grafía medieval sería latinizante por $u e$, y tanto $*_{Q} Q$ como *o románicas se cierran ante $-\mathrm{Cu}$-), de un *mōnó- o *munó-briga ${ }^{19}$; el punto de partida más plausible sería un celtibérico *mono-brig-, donde *mono- podría ser también 'montaña', la base de donde entonces derivan el britónico *mon-iio-, el topónimo británico Monā, así como el superlativo *mon-isama 'la muy montañosa' > Monesma, localidad que se encuentra en un llano desde donde se divisa la cadena Pirenaica en toda su majestuosidad. La relación de esos topónimos, que parecen remitirse a *mono-/ $\bar{a}$-, con un tema en dental *mon-(i) $t$ - sólo podría mantenerse postulando toda una cadena de hipótesis: dado que el romance aragonés conoció la simplificación de - $n d$ - en $-n$ - (v. gr., arag. med. quano < quando), tam-

pp. 314-317; las respectivas lecturas "anticeltizantes" o "celtizantes" dependen de lo cada investigador quiera demostrar.

18 Ma L. Albertos, 1980, p. 288, 1985, p. 177. Nótese que Munnius, Munninus son también nombres de origen latino.

19 Para la evolución *-ŏCŏ->-uC(u)é, cf. p.ej. culebra $<$ coluebra (cast. med.) < colobra. 
bién sería posible partir, en el caso de Munébrega, de *mondóbriga, como

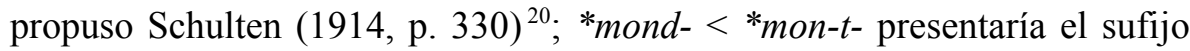
en grado cero, con el paso celtibérico $*_{-n t-} *_{-}^{*} n d$ - que postula Villar (1995, pp. 75-76). Admitido esto, la -o- sería una mera vocal de unión entre los miembros del compuesto, como la que aparece en los compuestos galos del tipo Ver-cinget-o-rix, donde -cinget- en un tema en dental (*keng-et-, irl. ant. cing, gen. cinged); por su parte, el superlativo *mond-isama $>$ Monesma se habría formado directamente a partir del mismo tema *mon-t-. Esto parece conducir a un tema alternante a partir de la raíz *men- 'elevarse, sobresalir' (lat. $\bar{e}-$, prō-minère; mentum 'mentón'): nom. sg. *mon-èt-s $>$ lat. Monèt-a, cib. monit-, con generalización del grado largo del nominativo (como en los temas en *-on- > cib. -ün-), e hisp.-occ. MVNID- 'monte' (divinizado); obsérvese que tendríamos un ejemplo de $* \bar{e}>\bar{\imath}$. Los casos débiles presentarían grado cero del sufijo: *mon-t-és $>$ lat. gen. sg. montis, reinterpretado como tema en $-i-$; cf. también gr. $\mu$ oṽ $\sigma \alpha<*$ Hóv $\tau$-j $\alpha$.

10. Dejando al margen lo excesivamente larga que es la acumulación de hipótesis requerida, esta teoría presenta otros inconvenientes formales. En primer lugar, no existe en indoeuropeo una alternancia del tipo propuesto, ${ }^{* *} C o C-\bar{e} t-/{ }^{*} C o C-t-$ : en las lenguas célticas los temas del tipo CéR(C)- $\breve{e} t-$, un modelo flexivo normalizado que resulta de la mezcla de los antiguos temas histero- y proterodinámicos, conocieron una cierta productividad (p. ej. *keng-et- 'guerrero', *uel-it- 'poeta', *oig-et- 'huésped' < *h

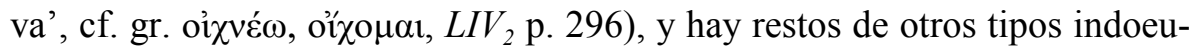
ropeos de temas en *-t- (*(p)luk-ot- 'ratón', irl. ant. luch; *nepot-, lat. nepos, irl. ant. nia 'sobrino', ogam gen. sg. NIOTTA; necht 'sobrina' < *nept-; *nei-t- 'campeón', irl. ant. nia), todos ellos con grado e o cero en la raíz; nunca con grado *-o-. Así las cosas, habría que postular todavía más hipótesis suplementarias: una posibilidad es considerar que el hispano-celta *monīt-, *mont- fuese la substitución de un acrostático **món-t-s, gen. sg. **mén-t-s: en latín, habría sufrido la misma tranformación que *nóku-t-s, *néku-t-s: nox, noctium; mons, montium. El tema con grado $e$ se habría conservado en el epíteto teonímico MENTOVIACO atestiguado en dos inscripciones procedentes de Zamora (v. B. Prósper, 2002, p. 338: de un topónimo *Ment-oui âa). Pero de ser así, no se entiende por qué en céltico no se creó a

20 Contra la identificación Munébrega = Munda, cf. A. Capalvo, 1996, p. 111, nota 574 y p. 116. Mi reconstrución Munébrega < *mon(d)o-brig-, sea con - $n$ - o con -nd-, no implica una ulterior identificación con la Munda donde tuvo lugar la batalla entre César y Pompeyo. 
partir del grado -e- un *menīt- *menet-, según el modelo de los temas en dental más productivos. Habrá que suponer entonces que el lat. mons (iacaso Monèta?), el brit. *moniio- y el hispano-céltico *moň̄t(o)-, *mont- o *mono- son la substitución, independiente en cada lengua, de un nombreraíz ${ }^{*} m \bar{o}(n),{ }^{*} m o n-{ }^{21}$. Y en cualquier caso, el tema en dental, sea cual sea su origen, nos lleva a trabajar con el sufijo *- $\overline{\bar{u}} k o-:$ si éste tuviese un valor meramente diminutivo como en galés y balto-eslavo, *monīt- $\breve{\bar{u}} k o$ - vendría a ser 'montañita', que no encaja en una tésera de hospitalidad, ni semántica ni sintácticamente. Podríamos darle al sufijo un matiz despectivo, y traducir *monìt- $\overline{\bar{u}} k o$ - por "montaraz, salvaje"; pero un sentido despectivo también parece fuera de lugar en una tésera de hospitalidad y, más aún, en un epíteto teonímico (Matres Monitucinae : "propias de los montaraces / salvajes"), así que el adjetivo en -uko-, despectivo en su origen o no, tendría que haberse convertido previamente en una designación étnica concreta.

11. Todavía se puede postular una etimología alternativa y, a mi juicio, más verosímil: moniTuuKoos puede contener el tema *moni- que aparece en irl. ant. muin (f.) 'protección', muinter 'familia, miembro del grupo familar; esposa legítima' < *moni-terāa- ${ }^{22}$; existe una variante de muinter sin palatalizar, más antigua, montar, de ${ }^{*}$ mono-terā- ${ }^{23}$. Formalmente también ese

21 El avéstico mati- citado por J. Pokorny, 1959, p. $726<* m n-t i-$ 'Vorsprung des Gebirges', recte Vd. 3, 20 upa maitīm; que ha de reinterpretarse como * matiiam = véd. matyà- (n.) 'garrote para machacar terrones', de mant(h)-, cf. Mayrhofer, EWAIA II, p. 298, con bibliografia.

22 Cf. Vendryes, 1958, pp. 309-311, De Bernardo, 1999, pp. 310 y 425-426. El tema *moni- 'protección' está relacionado con lat. manus < *mon-u-, umbro MANF 'mano', con la evolución fonética ${ }^{*} B o C V->* B a C V-\left(B=* m, * u,{ }^{*} K_{\sim}^{u}, i^{*} l l\right)$ propuesta por P. Schrijver, 1991, pp. 454-474, así como con germ. *mundō $\left(<* m n-t \frac{1}{a}-\right.$, la dental no puede ponerse en relación con la de *monĭt - ): isl. ant. mund 'mano', ingl. ant. mund, a.a.ant. munt 'mano' y también 'caución, garantía', y pervive en al. mod. Mund (f.) 'protección, tutela', Vormunt (m.) 'tutor', Mündel 'pupilo', cf. los NNP gót. Muntila, nord. ant. Myndill. La base para la evolución semántica la proporcionan conocidas expresiones latinas como in manu o sub manu esse.

23 En lat. in manu esse hace refencia al poder del marido sobre la esposa, o del pater familias; cf. además manumittere, etc.; en irl. y en germ. *moni-, *mono-, *mundō, hacen referencia a una tutela legal, no al resguardo que pueda ofrecer una fortificación. Por ello, para los topónimos celtibéricos *Mono-brig-, *Mon-isamā- (§ 9), y para la isla de Mona (Anglesey), caracterizada por un promontorio (Rivet y Smith, 1979, p. 420), sigue pareciendo más adecuado partir de un *mono- 'montaña'; Munébrega se encuentra en la conjunción de dos barrancos, y en las cercanías, camino de La Viñuela, se encuentran los restos un poblado celtibérico situado sobre un altozano. 
*moni- podría ser la base de derivación de MONIMAM, pero la semántica *mon-ī- 'recordar' (irl. ant. muinithir) propuesta por Gorrochategui, 1990, p. 309 sigue pareciendo más convincente. Se puede postular así un abstracto verbal *mon- $\breve{-}-t u$ - 'protección', formado a partir de un verbo denominativo en *-(e)ie- derivado de *mono- (cf. irl. ant. montar $)^{24}$, distinto del

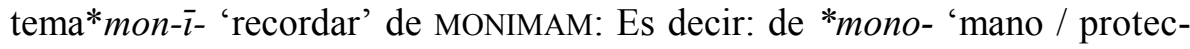
ción' se derivaría un verbo *mon-(e)ie-ti> * monĭti 'él tutela, protege', y de éste un abstracto verbal *mon- $\breve{-}-t u$ - 'protección legal, tutela'. Así pues, *monйtu-ko- vendría a significar más o menos 'tutelar, tutelado'; en nuestra tésera podría tener valor apelativo. Ciertamente, como la derivación en *-tupropuesta es poco económica, pues obliga a postular la hipótesis suplementaria de un verbo denominativo, todavía se puede encontrar otra alternativa: *moni-tuk-(o)- podría entenderse como compuesto de *moni- 'familia / tutela', y de un segundo miembro *tuk-o- cuya raíz aparece en indoiranio con el sentido de 'generación, descendencia': cf. el nombre-raíz ved. túc- (f.) 'descendencia, hijos' (RV), substituido en la lengua postrigvédica por toká- (n.) 'id. '; tókman- (n.) 'brote de cereal', av. rec. taoxman- (n.) 'simiente, parentela', pers. ant. taumā- (f.) 'familia', pers. mod. tuxm 'id.' (Mayrhofer, EWAIA I,651) ${ }^{25}$. Quizá esa raíz está presente en los antropónimos celtibéricos CONTVCI CIL II 3198 (Valeria de Arriba, Cuenca), NF CONTVCIANCO CIL II 3120 (Cabeza de Griego, Segóbriga), en composición con el preverbio *kom- ${ }^{26} \mathrm{~A}$ éstos testimonios se añade en el Occidente peninsular CONTVCI (Panoias, $A E 1983$, 465) y quizá Con[T]Vx (Golada, Pontevedra, $A E$ 1969$70,273)$. De ser cierta la lectura de éste último, acaso sería un resto del nombre-raíz, lo que a su vez deja abierta la posibilidad de que *monituk-os sea el genitivo de un tema en consonante. Quizá el nombre de individuo

24 El tipo derivativo está presente en céltico, p. ej. irl. ant. slond (tema en -o-) 'indicación, expresión' $\rightarrow$ verbo denominativo sluindid (A II) 'indicar, nombrar' $\rightarrow$ abstracto postverbal en *-tu- slondud, sloinded (tema en -u-) 'acto de nombrar, mención'; compuesto disluindi 'negar' $\rightarrow$ diltud 'negación'. El supino lat. monitum es formalmente similar al *monitu- propuesto, pero de *men 'pensar'.

25 Dat. sg. tuc-é, RV VI 48, 9, VIII 18, 18, VIII 27, 14; en RV IV, 1, 3 y V 41, 9 tujé, con sonorización pracritizante. Cf. K. H. Schmidt, 1985, p. 334: lus. TEVCOM, $-A E C O M=$ ai. tokám, y B. Prósper, 2002, pp. 79-80.

26 Albertos, 1979, p. 141 restituye respectivamente CONTVCIVS (podría ser -tucus) y $\operatorname{CONTVCIANCO}(n)$, entendido como gentilidad en gen. pl. Sin el preverbio, cf. VALERIVS TVCCo (CIL II 2763, Duratón, Segovia) y quizá lo atestigua también Marcial (III, 14): Romam petebat esuritor Tuccius | profectus ex Hispania. Pero Tuccius es también el conocido cognomen de una famila senatorial romana; no obstante, v. nota 28. 
ogámico Dovatukā/o-, gen. sg. - $\bar{a}$ - D[O]V[A]TUCEAS (M 431) ${ }^{27}$, y gen. sg. -oDOVATUCI (M 37), irl. ant. Dubthach, contenga un segundo miembro -tuk(a) , -tuko-, es decir: *dubu-o-tukā 'cuya descendencia es oscura' ${ }^{28}$.

12. En resumen, por un lado moniTuuKos puede ser un adjetivo étnico, determinando a iroreKiios; en ese caso tendría que ser un derivado en -ko- o $-\breve{\bar{u}} k o$ - de un topónimo, pero ya hemos visto en $\S \S 9-10$ la gran cantidad de dificultades formales que implica vincular directamente moniTuиKos con los topónimos *Mono-brig-, *Monisamā, que sí parecen contener un elemento léxico *mono- 'monte'; por lo dicho en la nota 23 , tampoco parece verosímil derivar los topónimos del supuesto *moni-(tu-) 'tutela'. Dado que en cualquier caso un NF en - $k o$ - tendría que aparecer en genitivo plural o singular ($k u m,-k o$ ), sólo queda la posibilidad de entenderlo como apelativo: o un compuesto moni-tuko- 'descendiente bajo tutela' (¿equivalente a 'hijo adoptivo', quizá referido a una institución similar a la daltacht irlandesa?), o un derivado en -ko- de un abstracto postverbal *monĭtu- 'protección, tutela', es decir, 'tutelado'. Con mucha menor verosimilitud, podría ser genitivo singular de

27 Antiguamente leído DOVATACIS; posiblemente masculino, ya que aparece latinizado en la misma inscripción como (gen. sg.) Dubtuci, cf. S. Ziegler, 1994, p. 170.

28 El primer miembro dova- es un derivado temático *dubu-o- de $* d u b u$, irl. ant. $d u b$ 'oscuro'; *dubuo- > pc. *duuo- > *douo-; para el detalle de la evolución fonética v. J. Uhlich, 1989. Por lo que respecta a -TUC-, McManus (1991, p. 108) lo entendía como un conglomerado sufijal, que, como señala Sabine Ziegler (1994, p. 170), no es analizable y carece de paralelos en irlandés. Ella parte de un derivado en $-\bar{a} k o-,{ }^{*} d u b u \bar{a} t-\bar{a} k o-$, del nombre verbal $d u b a d$ $<* d u b u-\bar{a}-$ to-, del verbo denominativo dubaid 'oscurecer(se)', aunque se ve obligada a admitir una grafía $<\mathrm{U}>$ para [ə] en *dubuāt-āko- $>* d o u a \theta \partial \chi a-$, resultado del debilitamiento de ciertas vocales, lo que no es inverosímil; pero no hay buenos ejemplos de ese procedimiento ortográfico. Los ejemplos más claros que aduce (Ziegler, 1.c., p. 51) presentan una $<\mathrm{A}>$ como grafía del debilitamiento vocálico: $*_{i}, *_{e}>[\partial]$, escrito $<\mathrm{A}>$ en CARRTTAC $<* k a r a t i k o-\mathrm{y}$ en

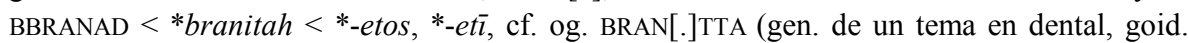

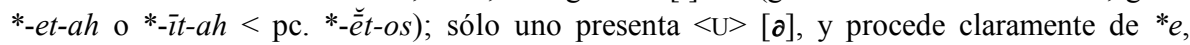
VOR(R)TIGURN < *-tigerno-. En CRONUN / CRONAN y [O]DARUN Ziegler no excluye la posibilidad de una falsa lectura por $<\mathrm{O}>$, y además en ambos casos la vocal debilitada es una $*_{a}<*_{O}$ con alargamiento compensatorio ante irl. prim. *- $\gamma n-:$ CRONUN / CRONAN, irl. ant. Crónán < goid. $*_{-} a-\gamma n o-<$ pc. $*_{-}-$-gno-, y no una $* \bar{a}$ antigua como lo sería en el caso del sufijo $*_{-}-\bar{k} k o-$ que ella postula. Con ser posible por lo que se refiere al ogámico, no creo que $<U>=[\partial]$ sea aplicable a la grafía latina Dubtuci, también con - $u$-. Por lo que respecta al tema en $\bar{a}$ masculino ${ }^{\circ}$ TUCEAS, acaso haya que compararlo con el cognomen de uno de los amigos de Virgilio y Horacio, Plotius Tucca: Wilhelm Schulze (1900, p. 375) incluyó Tucca, Tuccius en el listado de cognomina etruscos, pero quizá no se pueda rechazar un origen céltico al menos para una parte de los antropónimos en (-)tuc(c)-. 
*monituk-, bien apelativo - "iroreKiios, de la descendencia-bajo-tutela" -, bien NP como CON(T)VX, esto es, "iroreKiios, (hijo) de *Monituxs". Pero la explicación como nombre de persona queda excluida, como ya hemos dicho (§ 7), con el hecho de que *monituk(o)- es la base de la que deriva el epíteto de las Matres Monitucinae; como veremos a continuación, encaja mejor con las Matres un epíteto derivado de un étnico - que es lo usual - o, dado el caso, de un apelativo referido a una institución familiar.

13. Las Matres o Matronae de la Galia y Britania reciben en su mayoría epítetos derivados de étnicos ${ }^{29} \mathrm{o}$ de nombres de lugar ${ }^{30}$. Pero también reciben otros calificativos: así, la dedicatoria G-65 de Glanum se dirige a las

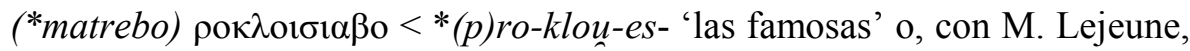
$R I G$ I, p. 79, 'las que escuchan, las que atienden'; y en Britania son típicas las Matres Transmarinae, advocación geográfica que tampoco es de origen propiamente étnico. En Hispania, dejando al margen los epítetos que reflejan cultos importados y que se dan en la Bética (MATRIBVS VETERIBVS en Porcuna, Jaén, AVfaniabVs en Carmona, Sevilla, AVGVstis en Reina, Badajoz), los epítetos de las Matres que se documentan son (siempre en dat. pl.) ${ }^{31}$ :

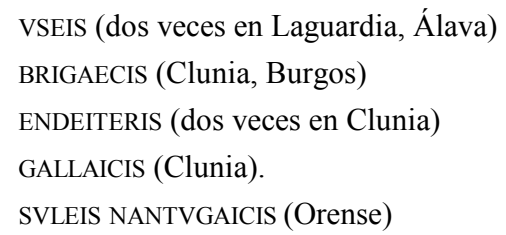

Dos de los cinco son claramente étnicos (Gallaicae, Brigaecae); las $\mathrm{Ma}$ tres Sule(v)iae de Orense también son un culto de origen extranjero, pero están provistas de un segundo epíteto de carácter étnico-geográfico (¿'nantu-ko- 'valle(cito)' / 'habitantes del valle'?, v. nota 14). Igualmente, el epíteto Brigaecae (así en Gómez-Pantoja, 1.c., var. lect. BRIGEACIS, cf. Villar, 1995, p. 132, nota 31) puede referirse a un topónimo *Brig $(\bar{a}) \sim * B r i-$

29 V. gr.: Ambirenses $\rightarrow$ etn. Ambireni, Eburnicae $\rightarrow$ etn. Eburones, Treverae...; es muy conocida la dedicatoria de Winchester (RIB 88): $\operatorname{MATRIB}(u s)$ ITALIS GERMANIS GAL(lis) BRIT(anis). El epíteto de las MATRIBVS OMNIVM GENTIVM (CIL VII, 887) es traducción exacta del epíteto céltico de las MATRIBVS OLLOTOTIS (RIB, 1030; <*ollo-tout-o-/-a-a).

30 Entre otros muchos: $\gamma \lambda \alpha v \varepsilon ı \kappa \alpha \beta o$ G-64 ? NL Glanum, $v \alpha \mu \alpha v \sigma \iota \kappa \alpha \beta$ G-203 ? NL Nemausus.

31 V. la lista de J. Gómez-Pantoja, 1999, pp. 422-423; TERMEGISTE en el epígrafe de Duratón (Segovia) es oscuro: puede ser un antropónimo (¿Ter(entius/a) Megiste?), a no ser que se restituya $\nmid$ Termegiste(nsis), de un topónimo emparentado con Termes $\sim$ Termeste ( ¿*term-ik-isto-?). Las Matribus Suleis Natugaicis no aparecen en la lista de Gómez Pantoja. 
giā, o quizá al propio brig- (= arx, cidadela) de Clunia: las Matres *Brig-ai$k \bar{a} s$ / -i $\bar{a} k \bar{a} s$ serían en ese caso las "Matres Oppidanas". Y de los otros dos epítetos, uno es un adjetivo en -tero-, *endi-tero- $>*$ endetero-, con $<\mathrm{EI}>$ por $e$ cerrada $^{32}$; posiblemente, *endetero - 'interior' hace alusión a unas $M a-$ tres propias de la ciudad (cf. las frecuentes dedicatorias británicas a las MATRIBVS SVIS, Holder II, cols. 464-467), por oposición, p. ej., a las Matres Gallaicae, foráneas pero también veneradas en Clunia ${ }^{33}$. Y finalmente, VSEIS también parece ser un adjetivo derivado de un preverbio, *us(s)eo- <

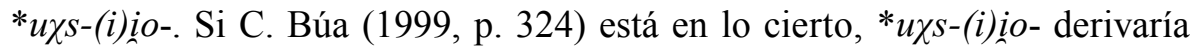
de un topónimo *UXso- 'elevado', pero también puede ser una mera alusion al emplazamiento del santuario de las Matres en cuestión (extremo que no sé si es comprobable), o referirse a las Matres mismas ${ }^{34}$. En resumen, las Matres Monitucinae pueden ser unas Matres *Monitucenses (étnico), pero en vista de la existencia de otros epítetos genéricos, no se puede excluir que

32 La grafía $<$ EI $>$ por $e$ cerrada $<*_{e}$, $*_{i}$ átonas no es rara en la zona occidental: MEIDV(G)EN(I)Vs < *medu-geno-; VECIVs (Lugo) : VEICIVs (El Bierzo, León), ARREINVS : ARRENVS (ambas variantes en Hispania Occidental), etc.; v. B. Prósper, 2002, pp. 386-387. Además, cf. el antropónimo ENDEGVS (Zamora), posiblemente [endegus]< *endikos. En Clunia, cf. $\operatorname{vsSEITICV}(m)$, v. nota 33; cf. en escritura ibérica are(i)KoraTa, -iKos A.52 vs. areK ${ }^{\circ}$ K.6.1. Las *-i- de *enditeros, *endikos son puramente sufijales: *endo : *endiko- es banal, para end-i-tero- cf. p. ej. el NP Doviterus, a no ser que se quiera suponer un preverbio *endien el que se habría producido un cruce analógico entre endo ${ }^{\circ} *\left(h_{1}\right)$ en-do (cf. el famoso teónimo lusitano Endovellicus, v. B. Prósper, 2002, pp. 346-351) y *andi- $<*\left(h_{1}\right) n$ - $d^{h} i$ o entre $*\left(h_{1}\right)$ en- $d o^{\circ}$ y eni (u otros preverbios en $-i$, p. ej. celtib. amPi-, gr. $\dot{\alpha} v \tau i$, żंí, i.a. adhi, etc.). El céltico hereda $*\left(h_{1}\right)$ en-do-, $*\left(h_{1}\right)$ en- $i$ y $*\left(h_{1}\right) n$ - $d h i$, confundidos de un modo u otro en irl. ant. in(d)- (en-, a-), galés yn, pero distinguibles aún en galo (Eni-/ Eno-, Endo-, And(e)-, Ando-: v. K. H. Schmidt, 1957, pp. 126-128, 205-208).

33 Aunque hubiera existido una conexión entre el culto cluniense a las Matres (siete altares en total) y las prácticas de fangoterapia en el santuario subterráneo de la "Cueva de Román”, como postula Gómez-Pantoja (1999, pp. 428-430), no parece posible que *endẹteroprovenga de un *andi-tero- 'inferior', una innovación del céltico cluniense que habría tenido que substituir a *andero- $<* n d^{h}$-er-o-, galo anderon, lat. inferus, y que además sería un caso de $* a N C$ - > eNC-, evolución que no está documentada en hispanocelta; los contraejemplos son legión: cib. amPi- K.1.1 passim, KamParoKum K.5.2, KanTom, -KanTam K.1.1, (es)anKios K.1.1, anTiom K.1.1, anToros K.0.10...; en la onomástica hisp.-occ.: Ambatus, Cantibidon(ensi), Cantunaeco, Nantugaicis...Para ARENTIO, -TIAE vs. ARANTA, ARANTO ${ }^{\circ}$, cf. B. Prósper, 2002, p. 99.

$34 \mathrm{M}^{\mathrm{a}}$ L. Albertos, 1979, p. 159, propuso una relación de vSEIS de Laguardia con el NF $\operatorname{VsSEITICV}(m)$ (Clunia). El NF parece derivar de un pp. *uxs-ito- 'subido, alzado' > *ússeto(con $* i$ átona $>*_{e}$ cerrada grafiada con $<\mathrm{EI}>$ ), o de una formación similar a lat. comes, -itis $<$

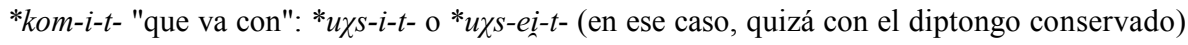
'que sube'. 
fuesen unas Matres *Familares (cf. las MATRIBVs DOMESTICIS, CIL VII, 915, 939 inter alia), o más bien *Tutelares.

14. La decisión final en torno a la función de moniTuuKos depende en parte de la interpretación que se le dé a aleTuures, y a la inversa. Lejeune $(1955$, p. 83) supuso, con muchas dudas, que aleTuures era el nominativo plural de un tema en $-r *$ are-dur-es, con disimilación $* r-r>l-r$, formado como $\operatorname{Ar}(e)$-morica a partir del nombre del río Duero (Durius), propuesta que recoge Untermann ( $M L H \mathrm{IV}$, p. 688). Esta interpretación obliga a pasar por la hipótesis suplementaria de la disimilación y, además, un adjetivo étnico derivado de un *duriio- debería presentar algún tipo de sufijación ( ${ }^{*}$ aredur(i)io-(ko)-, *are-dur-iko-?), como es típico en los numerosos derivados de esa clase formados a partir de nombres de ciudad que conocemos; $\mathrm{cf}$. además los étnicos Super- y Praestamarici, derivados en -iko- del nombre del río Tamaris. Como apoyo de la explicación de Lejeune, Untermann (MLH IV, p. 688) aduce la leyenda monetal roTurKom (A.87) < *ro-dur-ko«vor dem Durius», que al menos presenta un sufijo -ko-. En esta forma, que al ser una leyenda monetal en principio habría de tener un origen étnicogeográfico, se puede admitir una síncopa de ${ }^{*}$ ro-duriko- ${ }^{35}$, forma en la que se habría producido una substitución sufijal similar a la que se da en KonTe(r)Pia [kontreb-(i)ina $]$ frente a KonTePaKom [kontreb-ākom], es decir, *Dur-(i)io- $\rightarrow$ *-dur-iko-. Pero, con o sin síncopa, según la ley fonética postulada por Villar (1995, pp. 19-82) y aceptada por Untermann (MLH IV, pp. 394-395), en *ro-dur(i)ko se esperaría la lenición de $d$ intervocálica (esto es, †rozur(i)Kom ${ }^{36}$. Tampoco es posible establecer con claridad el vocalismo

35 Compárese con NP elauKo K.1.3, de *auiko-, igual que ARAVCIA < *arau-ik-iina - : ARAV(V)S; idéntica evolución en el NF CossovQ(um) <*-ouikūm (Sigüenza, CIL II, 2847); en CALNVS, CALNICVM (M ${ }^{\mathrm{a}}$ L. Albertos, 1979, 152), si es que son NNP celtas, también debió de haber síncopa, ya que de lo contrario se esperaría *-ln- $>$ *-ll-. En escritura ibérica hay dos formas en -rk- de difícil esclarecimiento: la primera, muTorKe K.9.7: si no es ibérico (que es lo más probable, al menos para el final en -e, que es la iberización usual de los nombres indoeuropeos en -os, -us), quizá proviene de un *mutor(r)ikei / -os relacionado con el NF muturiskum K.1.3, passim, derivado en -isko- del NP MVTVRRAE CIL II 5330; pero bajo la grafía muTorKe también podría suponerse un /mu(n)troko-/. La segunda es VIROBARCO ¿<*-ariko-?, junto a VIROBACOM en la misma inscripción ( $\mathrm{M}^{\mathrm{a}} \mathrm{A}$. Castellano y H. Jimeno, 1999) ¿Se trata de un error del grabador?

36 La interpretación roTurKo- $=*$ Rodur(i)ko-encontraría algún apoyo si ueizos (K.0.11, -ui K.6.1, 4): ueiTui (K.0.7) = */ueiðo-/, elazunos (K.1.3) : elaTunaKo (K.9.4) se admiten como casos de vacilación gráfica, cosa que no hace Untermann, v. MLH IV, p. 398. Naturalmente, esto no constituye un problema para quienes rechazan la lenición de $d$ intervocálica. 
original del hidrónimo: un $* d \bar{u} r(i)$ ino- abogaría al menos en favor de $* *$ rodur(i)ko-, pero también puede haber sido *dōr $(i) i{ }_{\text {io-, }}$ si están en lo cierto los romanistas que reconstruyen $*$ dorio- ${ }^{37}$ para las formas actuales del nombre del río (castellano Duero, leonés, gallego Doiro, portugués Douro), lo que haría preferibles, en principio, las formas con $-\check{\bar{o}}$ - que se documentan en parte de las fuentes griegas ${ }^{38}$. Ahora bien, lo cierto es que la llamada "inflexión de yod cuarta" - entre otros casos, lat. -óri- > romance *-ori- > *ọ́ir-, con vocal cerrada - hace que el resultado de $* \overline{\bar{o}}$ (tanto larga como breve) en ese contexto sea similar al de $*^{*}$ : ${ }^{*}$ corium $>$ cast. cuero, port. coiro; ${ }^{*} a(u)$ guriu $>$ cast. agüero, le. agüiro/agoiro. Y junto a -tōriu(s) > cast. med. -duero $>$ mod. -dero (que sospecho es el modelo que sirve a los romanistas para su reconstrucción del hidrónimo), cf. Coria, de Caurium, que representa una monoptongación secundaria a partir del mozárabe *Kauria. Todos estos factores hacen difícil determinar cual fue la forma original del hidrónimo.

15. En cualquier caso, no hay que otorgarle demasiado peso a la forma latina Durius, en las fuentes clásicas son comunes los casos de vacilación $u$ $\sim o$, especialmente ante $r$ :

\section{Calagurris}

Consaburensis (CIL II 4211),

Consaburrensis (Plin., N.H. III 25)
KalaKoriKos (A53)

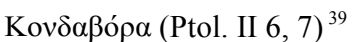

37 Cf. p. ej. Menéndez Pidal, 1940, p. 65.

$38 \Delta \omega$ píov Ptol. II 5.2, $\Delta$ opíov App., Hisp. 91, frente a las formas con $u$, p.ej. Durius en

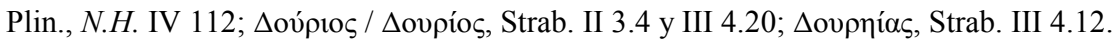

39 Sobre la alternancia - $n s^{-}:$: $n d$ - y sobre la alternancia -ur(r)- : -or- en este topónimo, v. F. Villar y P. Arboledas, 1999. La relación etimológica que estos autores plantean entre Consabur(r)a y la Sabora de la Bética (conservada al parecer en el topónimo actual Cerro de Sabora, sin diptongación románica), plausible como es, queda en el aire, ya que la epigrafía documenta las formas CONSABVRENSES (CIL II 4211): SABORENSES (CIL II 5450), con -ur- y or- respectivamente; si hemos de hacer caso a los resultados romances, el topónimo actual Sabora implica **Sabáura $\mathrm{o}^{* *}$-bōra (= SABORENSES); tanto la forma epigráfica latina como el topónimo romance son difíciles de explicar a partir de *-búrra. En cambio, Consabura, hoy Consuegra (Toledo), ha sufrido los efectos de la etimología popular y no es una buena fuente de información: parece ser la sustitución de un ${ }^{*} \operatorname{Co}(n)$ suebra $<* C o(n) \operatorname{só} b(\breve{V}) r a$, antes que del

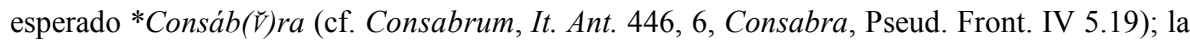
síncopa, quizás antigua, nos escamotea la vocal original, que debió de ser breve. Según el acento romance, la forma con -rr- de Plinio no parece genuina; también en la atestiguación epigráfica aparece - $r$ - simple y no doble. Ciertamente, en la atestiguación de Calagurris y Gracc(h)urris, tanto literaria como epigráfica, se da una oscilación entre -rr- y - $r$-, pero el testimonio romance es claro: Calahorra $<*$-gúrra. 


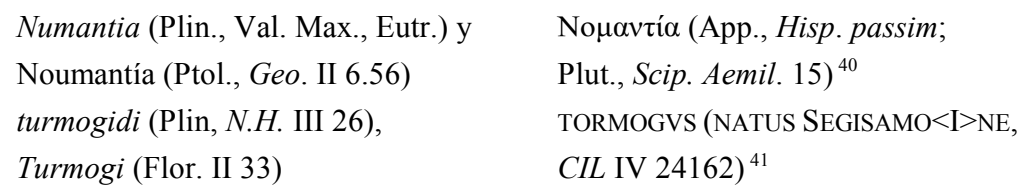

Estas vacilaciones en la transmisión literaria de topónimos y etnónimos se deben sobre todo a los rasgos específicos de las dos lenguas de recepción: el latín se inclina por el timbre $u$, el griego por el timbre $o$ - lo que a veces, por casualidad, puede estar más cerca de una forma celta original, pero no necesariamente -. Por su parte, el material antroponímico de las inscripciones latinas hispánicas proporciona por lo general grafías consistentes que, dado el caso, coinciden con el testimonio celtibérico, p. ej.:

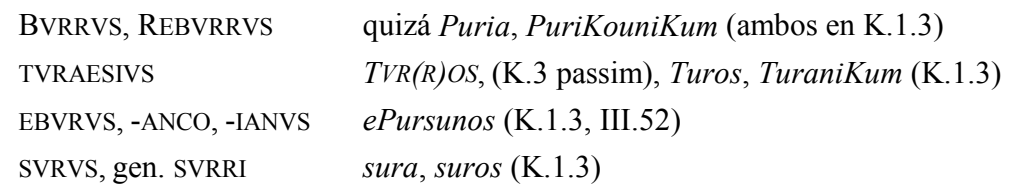

Dados casos como Clunia (Plin., N.H. III 27), K入ovvía (Ptol., Geo. II 6, $56 \mathrm{~N}$ ), que en las fuentes indígenas aparece con diptongo ou (A.67 KolounioKu, CLOVNIOQ [kloun-]), cabría postular incluso **dour (i)în- > *dọrio-, (interpretado por los latinos como $u$, por los griegos como $o$ ) $>$ romance *doriun.

16. Sea cual sea la explicación para roTurKom, desde el punto de vista formal el modo más simple de interpretar un tema celtibérico aleTur- dentro de la morfología indoeuropea sería postular un nombre de agente en *-tôr-, en el cual el vocalismo del nominativo se habría extendido a todos los casos, como sucede en latín (actor, -ōris), y también en celtibérico en los nombres en -u(n)-: leTonTu (K.1.1, b.1, 3), gen. sg. leTonTunos (K.1.3, II.60). En otro lugar (F. Rubio Orecilla, 1999-2000, p. 366) he sugerido que aleTurquizá pueda reflejar un *[allextūr-] $<*$ ad-leg-tōr: el preverbio ad- sería el mismo que se presupone, p. ej., en aseKaTi (K.1.1, a.6) < *ad-seg- o-sek- ${ }^{42}$;

40 Cf. el grafito sobre cerámica procedente de Numancia K.9.3 nouanTiKum, si es que hay que leerlo †nomanTiKum, posibilidad que excluye Untermann, MLH IV, p. 666, aunque menciona la otra opinión.

$41 \quad$ V. Ma L. Albertos, 1987, p. 184.

42 Cf. galo ad-ianto, Ad-bogius, Ad-magetobriga, etc.; v. Eska, 1989, pp. 37, 50; Meid 1993, p. 88; Villar 1995, p. 44 nota 29, Untermann, MLH IV, p. 409, etc. 
la raíz, la de irl. ant. laigid ${ }^{43}$ 'poner, tender(se) ${ }^{44}$, gót. ligan, esl. ant. -leže $\left(L I V_{2}\right.$, p. 398 , sv. *leg $\left.{ }^{h}-\right)$; el nombre de agente *allextūr designaría quizá a los "establecedores" del pacto reflejado en la tésera, que según lo que venimos diciendo ( $\S 6-7)$, serían irorekiios monituukoos, por un lado, y nemaios por otro. La hipótesis de que K.14.1 sea una tésera unilateral, donde se consigna a tres "establecedores" de un pacto, sin especificar el origen de los mismos ni con quién establecen dicho pacto carece de verosimilitud: incluso suponiendo que aleTuures fuese un cargo público, y que irorekiios, moniTuuKoos y nemaios fuesen tres magistrados, faltaría la designación local: compárese con el caso de la tésera de las Merchanas, citada en $\S 5$.

17. La interpretación de aleTuures como nominativo del plural de un nombre de agente en ${ }^{*}$-tor- plantea otro serio inconveniente: sería éste el único tema en *-tor- documentado como tal en céltico (v. § 20 sobre TerTurez), lo que justifica la reticencia de Wodtko (MLH V/1, p. 20). De hecho, en céltico insular los temas en -ter- sólo perviven en los nombres de parentesco; para los nombres de agente se emplean otras formaciones (cf. K. McCone, 1995), entre las cuales no se cuenta *-tor-. En las lenguas célticas insulares, no obstante, existe un cierto número de derivados en *-tro- (Perdersen, 1909-1913, vol. II, p. 45), y P. De Bernardo (1999, pp. 309-310) considera que unos pocos de ellos, con una semántica próxima a un nombre de agente, podrían representar la tematización secundaria del sufijo *-tor-/ tér- en céltico insular: irl. ant. ríathor (m.), galés ant. reatir, med. rhaeadr 'torrente' < *riiatro-, galés gwaladr 'líder, jefe' < *uelatro-, irl. ant. casar (f.) 'granizo' <*kאad-tr-ā, cf. lat. cadere. De ellos, sólo *uelatro-, con grado pleno de la raíz, podría ser la tematización del tema débil de un *ếlH-tor-; en los otros casos el vocalismo radical no está claro. Dado el carácter no productivo de estos derivados en *-tro-, cabe preguntarse si no se trata más bien de un mero desplazamiento funcional ciertos nomina instrumenti en *-tro-, similar al que se da en los abstractos verbales en -ti-, que suelen adoptar en céltico un significado concreto, cuya función a veces puede entenderse como "nombre de agente" (p. ej., irl. ant. flaith < *ulati- (f.) 'soberanía' > (m.) 'príncipe', irl. med. lá(i)th 'guerrero', fáith 'vidente' ...).

43 Con $a<* e$ breve, ante irl. prim. * $\gamma^{\prime} e$ no seguido de $-i-$, v. K. McCone, 1996, p. 111.

44 El galo legasit (L-67) se ha entendido por lo general como posuit; se trata de una inscripción funeraria en un vaso del s. III d.C., v. W. Meid, 1992, p. 18, P.-Y. Lambert, 1994, p. 137 y $R I G \mathrm{II} / 2$, pp. 209-210, con diversas alternativas. 
18. De Bernardo (1999, p. 308) propone además dos posibles ejemplos de temas de agente en -ter- en galo, ambos con una derivación ulterior formada al parecer a partir del grado pleno del sufijo: arKanToKo $<K>$ maTereK[o]s / ARGANTOCOMATERECVS (E-2: RIG II, pp. 26-37, bilingüe de Vercelli; el texto galo está en alfabeto de Lugano) y el NP LVXTIIRIO(S) (RIG IV, pp. 203204), Lucterius (Caes., B.G. VII, 5.1); ambos casos son discutibles. En general se suele admitir que el primero puede tratarse de un cargo público, paralelo al ARCANTODAN(nos) de las monedas de los Lexouii, los Mediomatrici y los Meldi. W. Meid, 1989, p. 12, puso en relación ${ }^{\circ}$ COMATERECVS < *komatriko- (sic, sin más explicaciones acerca del paso *-trik- > -TEREC-) con i.e. *meh ${ }^{-}$'medir', aduciendo el paralelo mesápico argora-pandes < *arguro-pondio-. Para De Bernardo 1.c., $\dagger^{\circ} \mathrm{kom}(\mathrm{m})$ ater- provendría en cambio de *kom-mo-ter-, paralelo al persa antiguo fra-mātāram (ac. sg.) 'mandatario, el que ordena'; la forma persa es un tema en ${ }^{*}$-tor-, con grado pleno de la raíz. Pero son posibles otras segmentaciones: P.-Y. Lambert (1994, p. 78) en principio no excluye la comparación evidente con el etnónimo Medio-matrici, pero finalmente explica ${ }^{\circ} \mathrm{COMATERECVS}$ con mucho ingenio como compuesto de *kom- 'con-' y *ater-iko- 'senador, noble', que a su vez sería un derivado de $*$ ater- 'padre' ${ }^{45}$ similar a lat. patricius, y con un desplazamiento semántico parejo. Así, el arganto-kom-ateriko-sería el pater (o patricius) con(scriptus) encargado de la acuñación de moneda; obsérvese que en cambio, si se recurre a un nombre de agente en -ter- como hacen Meid y De Bernardo, queda sin explicación la función del sufijo -iko-. Por lo que respecta a Lucterius, al tratarse de un NP habría que descartar antes su pertencia a las series antroponímicas formadas con sufijos -er(i)o- (Tritanerus, Kı́ńpıs, Daverius...), -ar(i)o- (Carnarus, Cambarius...), -ir(i)o(Caciros, Meððirius ...), -ur(i)o- (Vimpurilla, Caturus...), quizá sobre la base *luk(o)t- 'ratón', que también aparece en otros nombre propios, cf. LVCO-

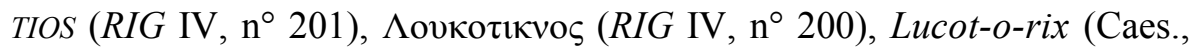
B.G. V, 22, 2). O, porqué no, se podría suponer así mismo una síncopa o haplología a partir de comparativos *luk-itero-, *lug-itero-, *luk(o)t-itero-. Así pues, tanto -komater-ecus como Lucter-ius son ambiguos y distan mucho de servir como testimonio de la existencia en céltico de nombres de agente en -ter-, -tor-.

45 Cf. los NNP derivados Aterus, -onius (Holder, I, cols. 258-259), Matera, -ia, -illa, -i $\bar{u}$ (Holder, II, col. 459). X. Delamarre, 2001, p. 102 (con bibliografía), señala que el proto-eslavo *kŭmotrŭ 'colega' podría reflejar un préstamo céltico oriental *kom-atr-o- 'com-padre'. 
19. En celtibérico tampoco hay buenos candidatos a nombres de agente en -ter-. El vocalismo del genitivo TuaTeros (nombre de parentesco en -ter-), con extensión del grado -e- de los casos fuertes, o, quizá, si $* \bar{e}$ se conservó en celtibérico, con la extensión de la $\bar{e}$ del nominativo según el patrón conocido en los temas en $-\bar{u} n$-, parece excluir en principio que anTiros ${ }^{46}$, PilTirei (ambos en K.0.10) sean casos débiles de sustantivos en *-tìr- $<*$-tèr. Hay una forma con una secuencia -ter- ${ }^{47}$ en el IV bronce de Botorrita, sToTeroi, de interpretación compleja. Los editores del bronce (F. Villar y C. Jordán, 2001, pp. 113-114) parten de * stâter-o- ${ }^{48}$ y postulan de modo muy especulativo, como ellos mismos reconocen, que una $\bar{a}$ protocéltica $\left(<* \bar{a},{ }^{*} \bar{o}\right)$ en sílaba no final átona aparecería como $o$ a través de una fusión de timbre $* \bar{a} / * \bar{o}$ $>* \stackrel{\circ}{a}>o$ (¿sólo gráfica?) - justo al revés que en el resto de las lenguas celtas, donde $* \bar{a} \mathrm{y} * \bar{o}$ en sílaba no final se confunden en $* \bar{a}-{ }^{49}$, señalando de paso que no hay buenos ejemplos para la evolución de $\bar{a}$ en ese contexto en celtibérico; lo cual, dado el magro corpus de que disponemos se puede aplicar

46 Var. lect. anToros, posibles lecturas *[antros] y *[antoros]. Si no es un antropónimo en nom. sg. (así Untermann, MLH IV, p. 553), podría ser un elemento adverbial usado como preposición de (dativo-)locativo, similar a enTor-kue TouTam [ del IV bronce de Botorrita (BB.IV, a.1, v. F. Villar y C. Jordán, $\left.2001_{\mathrm{b}}, 119-120\right) . i^{*}\left(h_{1}\right)$ én-tor $>$ entor vs. * $\left(h_{1}\right) n$-tr-és ? */antros/? ¿O, si se lee $<n T>=/ n d /$, de *nodh-(e)r $>$ pc. *ander- '(de)bajo'?

47 Evidentemente, no todas las formas que contengan -ter-podrán ser analizadas como nombres de agente en -ter-; el sufijo contrastivo *-tero-, comparativo *-(is)-tero- está presente en la onomástica hispano-céltica: además del ENDEITERIS citado en $\S 13$, cf. NP fem. elKua (K.1.3, tres veces) : cpvo. ElgVISTERVS CIL II 2613 (Zamora), junto a un posible spvo. ELGVISMIQ(um) CIL II 3061 (Madrid) < *-is(a)mo- + -iko-; además, quizá DOVITERVs /-DERVS ( $\mathrm{M}^{\mathrm{a}}$ L. Albertos, 1987, pp. 171-172). LesTera (K.1.3, E.1) es también una formación en *-tero-; en principio la lectura *[lestra] a que obliga la conexión etimológica con el galés llestr 'recipiente' (De Bernardo, 1999, p. 371, nota 196; con mucha reserva De Hoz, 1996, p. 200, siguiendo una sugerencia de Lambert) ha de rechazarse, pues va contra la norma ortográfica $-P i-r-i-=[b r i]$, cf. p. ej. cib. enTara con una p o sible lectura *[entră $]$ (no **enTera).

48 Si fuese una tematización secundaria a partir de un verdadero tema en -tér-, la forma de partida sería *stāter- (cf. gr. $\sigma \tau \alpha \tau \eta ́ \rho ~<*_{\text {sth }}$-tér-, distinto de lat. stātōr $<*_{\text {stéh }}$-tor-), lo que no permite explicar la $o$ de sto-, como implican TuaTer, con $-a-<$ pc. *ăter- $<$ ie. *-h $\left.h_{2} t e ́ r-\right), \operatorname{TaTuz}\left(\mathrm{K} .1 .1\right.$, a) $<* d h_{3}$ - o $* d h^{2} h_{1}-t o \bar{d}$. Ciertamente, el indio antiguo presenta extensión del grado pleno en ambos tipos de derivado (sthātár-, sthătar-), pero una extensión analógica de esa naturaleza en celtibérico es indemostrable, aunque no improbable ... si *-ter-y *-tor- hubieran sido formaciones productivas en céltico.

49 El propio Villar, 1997, pp. 931-932, explica KomPalKez como «perfecto en * ${ }^{*} \bar{\emptyset}$ » (*-bốlg- $>*$ *bắlg-]). En cualquier caso, cf. la propuesta de Hamp, 1989, Eska, 1989, p. 57 (KomPalKez como adj. en $*_{-s k o-)}$, que fácilmente puede reinterpretarse como un tema de pre-

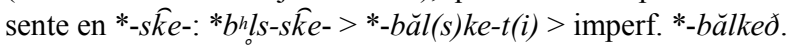


sólo a sToTeroi ..., y únicamente si se admite una acentuación *[ståtéroi] o *[-terói ], cosa por desgracia indemostrable: el argumento peca de circularidad. Por lo que respecta al tratamiento de $\bar{a}$, recientemente el propio Villar (1999) publicaba una tésera con un caso plausible de $\bar{a}$ en sílaba no final posiblemente tónica - que preserva el timbre, slaniaz $<*$ slān(i)iā-, cf. irl. ant. slán 'sano' y el hidrónimo Sláine, así como lep. slaniai (F. Villar, 1999, p. 553). Y además hay numerosos ejemplos del sufijo céltico *-āko- (seKilaKo K.0.11, elaTunaKo K.9.4, uarakos A:59); en la toponimia hispánica y en los préstamos celtas al iberorromance el sufijo en unos casos presenta la acentuación románica (Luzaga, Litago, aliaga / aulaga), en otros parece que no (Trébago, bálago); ¿habría que suponer que el sufijo celtibérico -okoproviene de $*-\stackrel{\circ}{a} k o$ - átono? Dados los problemas formales y fonéticos que surgen al partir de un **stāter-, no parece haber mejor alternativa que la de C. Jordán (F. Villar y C. Jordán, 2001, p. 114 nota 48), quien analiza sToTeroi como un derivado en -tero- a partir de un tema pronominal sto- cuyo acusativo femenino se documenta en el bronce de Luzaga (K.6.1, 6), stam kortikam. Ciertamente, como apuntan Villar y Jordán en la citada nota, la productividad de los derivados en -tero- a partir de temas pronominales es muy limitada, tanto en céltico como en otras lenguas: por lo general las formaciones con el sufijo contrastivo -tero- quedan restringidas a ciertos posesivos, al tema interrogativo $* k^{u} O-$-, a los indefinidos de oposición (p. ej. lat. alter, gót. anpar) y los adjetivos de oposición espacial (p. ej., lat. dexter, sinister). A falta de mejor opción, habrá que admitir que el sufijo contrastivo -tero- se aplicó en celtibérico al tema demostrativo $s T o-/ a$-. En cualquier caso, sToTeroi no es un buen candidato a derivado de tema en - ter $^{5}{ }^{50}$.

20. Pero la ausencia de nombres de agente en -ter- en céltico no es tan grave como la carencia de temas en -tor-paralelos al supuesto *allextūr-. La única forma similar sería TerTurez $(\mathrm{K} .0 .14, \mathrm{~b} 4)$, en la segunda cara del bronce "Res" ${ }^{51}$, que al menos en lo formal podría analizarse como un tema

$50 \quad$ Posibles lecturas como ${ }^{* *}$ sto $\chi$ tero-, ${ }^{* *}$ st $(r) o(n) \chi$ tero-, etc., no conducen a etimologías viables; suponer una monoptongación a partir de un ${ }^{* *}$ stou $(\chi)$-ter- implicaría de nuevo un grado pleno en la raíz, y se plantearían problemas fonéticos, ya que el paso ou $>o$ carece de buenos paralelos en la epigrafía celtibérica. F. Rodríguez Adrados, 2002, pp. 5-6 recurre a

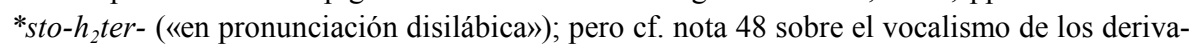
dos en *-ter-.

51 Como siempre que se menciona el bronce "Res", no creo inoportuno subrayar las dudas que subsisten en torno a la autenticidad de dicha pieza, como F. Villar 1996, p. 32, nota 74 pone de manifiesto; cf. J. Untermann, $M L H$ IV, p. 558 («la autenticidad de la inscripción 
en *-tōr-, con la desinencia -ez propia del ablativo los temas consonánticos; pero Villar (1995, pp. 32-33 y 1997, pp. 931-932) lo identifica como forma verbal, lo que resulta más esclarecedor, al menos desde el punto de vista sintáctico ${ }^{52}$.

21. Si aleTuures no es un nominativo plural que califique a los partícipes del pacto, ha de ser un nominativo singular calificando al NP nemaios. Podría ser un compuesto con Tures (K.0.7, Torrijo), en el caso de que esta palabra fuese, por ejemplo, el nominativo de un tema en ${ }^{*}-e(n) t^{53}$. Un primer miembo ale- apenas puede ser otra cosa - etimología in extremis - que $*[$ alle $]<*$ al(l) ei, locativo singular monoptongado de *allo- 'otro'; nemaios sería entonces el "Tures en otro (lugar)", suponiendo que Tures fuese un cargo público, ya que se repite de un modo formular en los bronces de Medinaceli (K.0.7) y Torrijo (cf. nota 53). Otro ejemplo de locativo singular como primer miembro de compuesto en celtibérico podría ser uameisTe (K.0.14, a.3), según la etimología postulada por Meid (1996, pp. 31-32): uameisTe <

con la información de que hoy disponemos no puede ni rechazarse ni confirmarse»), W. Meid, 1996, p. 26 ( «A causa de su poco claro origen no se puede excluir por completo la posibilidad de una falsificación»), De Hoz 1999, 457 («Dejo de lado el llamado "bronce res”, cuya autenticidad me sigue pareciendo dudosa...»).

52 F. Villar, 11.cc., postula un perfecto *tertōre recaracterizado mediante la desinencia secundaria $*_{-} t>*_{-} \partial$, de «una de las muchas raíces ter» que el diccionario de Pokorny ofrece; $* \bar{o}$ no ha pasado a protocelta $* \bar{a}$ en sílaba interior pues para Villar $(1997$, p. 932 , nota 130 ), $*_{\bar{o}}$ átona $>\bar{u}$ : es decir, *tértōret. Esto puede ser una restricción fonética razonable, especialmente si se encontrasen más ejemplos, pero: 1) los perfectos en vocal larga no tienen tema reduplicado (cf. supra nota 49 la etimología de Villar para KomPalKez); 2) una reduplicación plena no nos lleva a un perfecto, sino a un presente intensivo (tipo lat. murmurare, gr. $\pi \alpha \mu-$ paív(). TerTurez sería, formalmente, un imperfecto intensivo temático de un tema verbal Tur- (cf. quizá Tures i $3^{\mathrm{a}}$ sg. ${ }^{*}-s-t$ ? en los bronces de Medinaceli (K.0.7) y Torrijo, v. nota 53). El problema de la reduplicación se eliminaría si Ter- fuese un preverbio: con una lectura $\mid$ trēe- $<*$ trei (¿monoptongación en proclisis?), se podría comparar con galo tre-, tri-, irl. ant. tre, tri, galés med. trwy, try- 'a través de'. En definitiva, nada seguro.

53 En F. Rubio Orecilla, 1999-2000, pp. 153-154, planteé varias alternativas etimológicas para Tures como $3^{\mathrm{a}} \mathrm{sg}$. de un pretérito sigmático en ${ }^{*} s-t$. Por supuesto, queda abierta la posibilidad de que sea un tema en dental *T $\overline{\bar{u}} r(r)$-et-s, y en ese caso Tures PunTalos KorTonei se interpretaría como "Buntalos (fue/es) Tures en Cortono". Pero dado que para un tema en dental, especialmente si es un nombre de agente, se espera un grado $e$ en la raíz por ser el tipo más productivo, cf. $\S 10$, quizás haya que postular un tema participial $*_{-} e n t-s>$ cib. $*_{-} e(t) s \sim$ *ēs. Es una posibilidad que resulta interesante si en el bronce "Res" se lee $(\mathcal{X})$ 准 res como $\dagger($ Pi $)$ Peres $=[$ berēs $]$ o $[$ bibrēes $]<*\left(b^{h} i\right) b^{h}(e) r$-ents (atemático *-ént-: *-not-), cf. lat. ferens, ind. ant. bibhrat-; sobre la lectura en cuestión, cf. Wodtko, $M L H \mathrm{~V} / 1$, p. 301. 
*u(p) ${ }^{\circ} m e i-s t h_{2}-e i$ (dat.) ‘que está en lo más alto'; en ese caso, habría que admitir que la monoptongación sólo se produjo en sílaba final, con lo que la ecuación $*[$ allēe $]<$ al(l)ei queda en entredicho; al menos para uameisTe hay paralelos indoiranios (p. ej., rathé-șth-a- o ${ }^{\circ}$-ṣth $(\bar{a})$ - 'que está sobre el carro') ${ }^{54}$. En cualquier caso, la hipótesis*al(l)ei-Tures implica la curiosa expresión de una magistratura ... sin indicar la comunidad o lugar que tal magistratura representa, salvo mediante un indefinido; cf. en cambio K.0.7 Tures...KorTonei, Torrijo Tures...KoTizonei, en ambos casos con locativo.

22. Si se admite que el celtibérico conservó la $* \bar{e}-$ lo cual es una mera posibilidad, a falta de ejemplos definitivos a favor o en contra -, queda abierta la puerta para explicar aleTuures como un compuesto en $* r \bar{e} \chi s$, y entonces salta a la vista la similitud de aleTuures con el NP galo $\uparrow$ Alle $<t$ $>$ orix (Nîmes), ya señalada por De Hoz y Michelena (1974, p. 75). Para el NP galo Holder, en I, col. 95, dio la lectura ALLEYORIGI CAPPRAI (F.) IVLIA VXOR (CIL XII 3396), pero en III, col. 569, lo enmendó como ALLETORIGI CAPPRAi ... (BELA?)TVLLA VXOR. K. H. Schmidt (1957, p. 121) y Evans (1967, p. 133) admitieron con reservas la corrección de Holder ${ }^{55}$. K. H. Schmidt (1.c., p. 122) propuso un primer miembro *alleto-, derivado de *allo- 'otro' y que sería un derivado similar al que aparece, según él, con síncopa y distinto grado vocálico en el sufijo, en el nombre de una tribu cántabra citada por Estrabón (Strab., III 3.7), los $\alpha \lambda \lambda$ ó $\rho_{\rho} \gamma \alpha \varsigma$ (ac. pl.), étnico que como K. H. Schmidt señala tendría una atractiva traducción, *alloto-rìg- ${ }^{56}$ 'que son reyes sobre los demás'. Según K. H. Schmidt, la misma síncopa ${ }^{57}$

54 No obstante, se puede postular una alternativa: uameis-Te como gen. sg. de un tema en $-i$, seguido de la partícula *de y concordando con el NP reTuKeno: uameis-Te ainoliKum reTuKeno “... y / pero del *uami- de los Ainólikos (llamado) Rextugenos ..."; se trataría de una nueva oración, tras KueKueTiKui neKue esozeres neKue esianTo, si esozeres y esianTo se consideran formas verbales finitas, v. F. Rubio Orecilla, 1996. Este tema en -i- *uami- podría ser una variante, una substantivación, del uvamo- < *up ${ }^{\circ} m o$ - 'elevado' presente en el NP lepóntico Uvamo-Kozis ( $\left.<* u{ }^{\circ}{ }^{\circ}{ }^{2}-g^{h} o s t i-\right)$.

55 Id. Billy, 1993; Whatmough, 1970, p. 199 da una lectura *Alletroris, pero como señala Evans, 1.c. nota 10, ha de tratarse de un error.

56 En rigor, habría que pensar en sufijos distintos, -to- añadido directamente al tema promonimal *allo- y -et-o-, relativamente productivo en céltico, pero no esperable en principio en un tema pronominal. Como ejemplo de *alleto- K. H. Schmidt no cita $A \lambda \lambda \varepsilon \tau[\varepsilon$ l $]$ vo $\varsigma$, $R I G$ I, G-224.

${ }^{57}$ K. H. Schmidt, 1957, pp. 92, 101, presenta algunos casos de síncopa -ter-, -der- (no

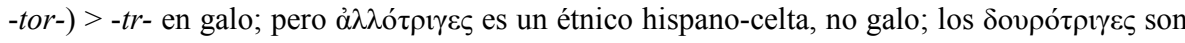
britanos, aunque podría ser un étnico transmitido a los romanos por los galos. 


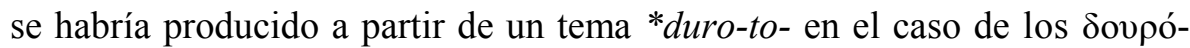
$\tau \rho \imath \gamma \varepsilon \varsigma$ (Ptol. II 3.13), tribu de la Britania meridional, cuya capital era Durnovaria, en la costa del Dorchester actual. ¿Hemos de entender acaso que el Nemaios de K.14.1 es un alótrige, vecino de los túrmogos de Segisamô? Desde un punto de vista fonético la etimología $\alpha \lambda \lambda o ́ \tau \rho ı \gamma-<* a l l o t(o)-r i ̄ g$ sería muy relevante, por cuanto documentaría en la forma griega el paso $* \bar{e}$ $>\bar{l}$ al menos en un dialecto hispano-céltico septentrional...y que no se habría producido en aleTuures, donde además se habría dado un molesto cierre -o-

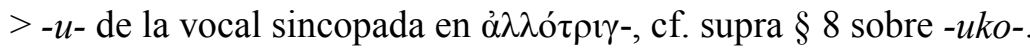

23. Además, los $\dot{\alpha} \lambda \lambda$ ó $\rho \imath \gamma \varepsilon \varsigma$ de Estrabón parecen corresponder a los $\alpha \hat{\text { - }}$

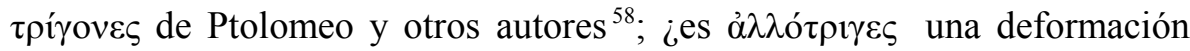

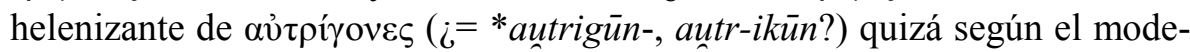
lo de gr. $\dot{\alpha} \lambda \lambda$ ó $\rho \rho \varsigma \varsigma$ 'ajeno, extraño'? Podría serlo, quizá, con respecto a un étnico *alleto-rīg-, homónimo del NP galo $\uparrow$ Alle $<t>$ orix; también se podría postular un hispano-celta *allot(e)r-iko-, derivado de un*allo-tero-, tema pronominal extendido con el usual sufijo contrastivo y quizá aplicado a los autrigones por otras etnias. Ahora bien, dado que allo- (y duro-) son temas bien atestiguados en la onomástica y etnonimia célticas, quizá sea más correcto admitir un segundo miembro -trig(o)-, aun de etimología desconoci$\mathrm{da}$, antes que postular unos temas $\operatorname{allot}(0)-, \operatorname{durot}(o){ }_{-}^{59}$ y unas síncopas ad

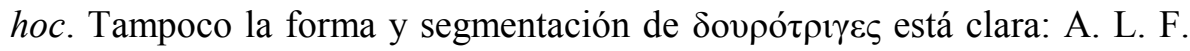
Rivet y C. Smith $(1979$, p. 352) s.v. Durotriges advierten que «it is by no means certain that the name has $-i-\gg-$ pese a que toda la tradición manuscrita de Ptolomeo concuerda en ese punto -, pues la epigrafía documenta ese étnico como CI(uitas) DVROTRAG(um) (RIB 1673). En ese caso, ese segundo elemento -trag- podría estar emparentado con irl. tráig $<*$ trāgi- 'playa, bajamar' (cf. lat. trahō; en ese caso, *dūro-trāg-(i)- sería en origen designación geográfica: ¿'los de la playa lejana / fortificada'?), y entonces habría que

58 Ptol. II 6.7, Plin., N.H. III 27; la variante Autricones de Liv., frag. 22, es un caso banal de confusión gráfica $\mathrm{G} \sim \mathrm{C}$.

59 La existencia de un tema *düro-t(o)- no pasa de ser una hipótesis: Holder I, col. 1386 postula un posible tema *dūroto- para NL Durotincum, NP Durotix; pero éste último está formado sobre modelos como Calitix < *kaleto- 'duro, fuerte', que a su vez toma el elemento -ig- de los nombres en -rixx. Por lo que respecta al NL Durotincum, contando con que -inkosea sufijal y no parte de un segundo miembro *tinko-/*tenko-, se podría pensar en *du-roto'de malos carros / ruedas', o 'malo para las ruedas, de malos caminos', cf. NNL Roto-ialos, Roto-vallum, irl. ant. roth 'rueda, disco' y, para la formación, los NNP Du-rati, Du-rat, K. H. Schmidt, 1957, pp. 198, a los que hay que añadir Duratius Caes., Gall. VIII 26. 


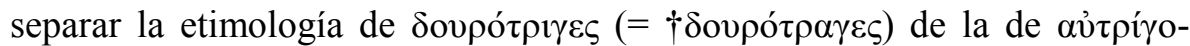
$v \varepsilon \varsigma^{60}$. En definitiva, la triple identificación aleTuures: $\uparrow$ Alle $<t>$ orix $: \dot{\alpha} \lambda \lambda o^{-}$ $\tau \rho \imath$ - implica demasiados problemas: por más que verosímil, la lectura del NP galo no pasa de ser una conjetura ${ }^{61}$; la etimología y forma última del étnico $\alpha \lambda \lambda o ́ \tau \rho$ y $\alpha \varsigma$ tampoco son seguras; finalmente, ni la - $u$ - ni la -e- de aleTuures junto a la -i- de - $\tau \rho \imath \gamma$ - tendrían una explicación fácil. La última posibilidad es suponer que aleTuures fuese un genitivo de filiación, bien de un tema en $-i{ }_{-}^{62}$, bien de un tema en consonante, como PunTunes (cf. nota 2); pero esto último nos lleva de nuevo al incómodo tema en $-r$ -

24. Queda por analizar la primera palabra de la tésera de Sasamón, iroreKiios. En apariencia se trata de un compuesto con un segundo miembro -rě̄gprovisto de un sufijo -(i)io-, y un primer miembro iro- ${ }^{63}$. La relación de este

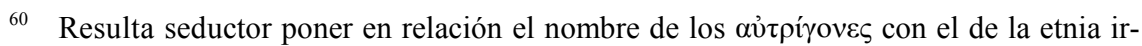
landesa de los av̉ĩvor (Ptol. II 2.4), irl. Uaithni <*(p)aut

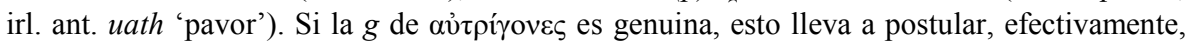
*(p)aut(o)- o *(p)au(e)t-rēg(-ōn), con síncopa o con grado cero del tema en dental *(p)au-t-> *aut-rīg-(ün-) 'rey terrible, temido'. De ser así, tendríamos, junto al topónimo Rixama (Mar-

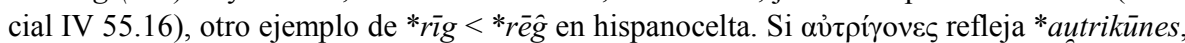
quizá haya que postular un adjetivo *(p)aut-ro- 'terrible', presente quizá también en el nom-

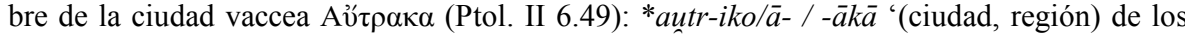
temibles (*autro-)' $\rightarrow$ *autr-ik-ūn- 'habitante de dicha región/ ciudad'; si Ptolomeo situó correctamente Aứ $\rho \alpha \kappa \alpha, * a u t r-i k o / \bar{a}-\mathrm{y} * a u t r-\bar{a} k \bar{a}$ no se referirían a la misma entidad geográfica, dada la distancia entre vacceos y autrigones. Algo menos plausible como base de Aǘ $\rho \alpha \kappa \alpha$, *autr-iko- sería una forma sincopada de un derivado contrastivo del preverbio au, *au-t(e)ro'el de más lejos'.

${ }^{61}$ ¿Podría leerse la Y como V? Es decir, $\uparrow$ Alle $<v>$ orix $=*$ ad-lēuo-; v. en X. Delamarre, 2001, p. 169, los derivados de un tema lēuo-: etn. Levaci, NP Levacus, -anius, NL Duro-levo, Levio-dunum, etc.

${ }^{62}$ En el caso muy difícil de demostrar de que el TureiPo de Uxama (K.23.2) fuese un dat.-abl. pl. dialectal de un tema en $*_{-i-}-e i P_{o} *[-e b o]<*_{-i-b o(s)}$ (cf. F. Rubio Orecilla, 2003, p. 144, nota 4), el supuesto gen. sg. (ale-) Tuures podría pertenecer a ese paradigma; pero alecomo primer miembro no es especialmente satisfactorio, v. $\S 21$. No parece haber conexión posible entre ese presunto tema en $-i$ - TureiPo $i<*_{-i-b o}(s)$ ? con el Tures de Medinaceli (K.0.7) y Torrijo: en el paradigma de un tema en - $i$ - Tures sólo podría entenderse como gen. sg. monoptongado *[-es]<*-eis, pero en ambas inscripciones se grafía el diptongo en sílaba final: K.0.7 KorTonei, Torrijo TerKininei, KoTizonei, y si Tures es una forma nominal y no verbal, es más adecuado sintácticamente un nominativo, cf. nota 53 .

${ }^{63}$ Lejeune (1.c.) leyó Kuiro ${ }^{\circ}$, pero Untermann (l.c.) prefiere la lectura de Gómez Moreno, ya que al fin y al cabo éste último vio en persona la inscripción, hoy desaparecida, y explicó que lo que en su dibujo aparece como $\odot$ ha de entenderse como un elemento decorativo; en cualquier caso, la lectura Kuiro ${ }^{\circ}$ tampoco ofrece mejores posibilidades de identifica- 
iro- con el NF IRRICO(n) (CIL II 2943, Izana, Soria) es bastante plausible ${ }^{64}$, lo cual lleva a considerar iroreKiios preferentemente un antropónimo. Untermann (MLH IV, pp. 426 y 688), que parte de la identificación de moniTuuKoos (: Monitucinae) como étnico, señala que la sufijación en -(i)îno- de un NP en *-rē $x s$ no estaría motivada, de modo que la solución de P. de Bernardo (1996, p. 237, nota 130) parece en principio adecuada: podría tratarse de un compuesto de rección verbal o un derivado de la raíz * $\left(h_{3}\right) r e \hat{g}$ - 'dirigir', con $e$ original en cualquier caso. El sufijo -(i)io- en las lenguas célticas insulares se emplea, entre otras cosas, para la formación de nombres de agente, cf. p. ej. galés prydydd $<*$ kurit-iiio- 'poeta' $\leftarrow$ pryd 'forma' $(<* k u r i t u-)$ o air. creth 'poesía' (<*kurito-); esto es, 'reg-iio- 'que rige'. Esa identificación etimológica de -reKiios dejaría suponer, como alternativa, que iroreKiios fuese un tipo de función pública y no un nombre propio; en ese caso, el pacto se habría concertado entre un magistrado, "el que rige el * mado) Nemaios", y un o unos aleTuures: moniTuuKos habría de ser necesariamente la designación étnica del magistrado, y aleTuures también tendría que ser identificativo: o NP en singular o étnico, en singular o plural. Pero hay otras muchas posibilidades: si moniTuuKos es un antropónimo, como sugieren CONTVCIVS, CONTVCIANCO, CON(T)VX, Tuccius (§ 11), entonces estamos ante un pacto entre el iroreKiios Monitukos y Nemaios; aleTuures podría concertar con el segundo, o con ambos, los dos "establecedores" (§ 16). Y porqué no, rizando el rizo, también podría ser que el iroreKiios monitucense, o un iroreKiios 'montañés', o iroreKiios (NP), 'el de la tutela' hubiera servido de garante en el pacto entre nemaios y aleTuures. Desgraciadamente todo esto queda en el aire, ya que además desconocemos el sentido apelativo que pueda haber tenido $* \overline{\bar{i}} r(r) o$ - (que podría dar sentido a una traducción como magistratura). Por otro lado, lo usual es que los nombres de agente en -(i)ino- aparezcan con grado $o$ en la raíz, mientras que los abstractos verbales en *-(i)io-, *-(i)ia $\bar{a}$ - presentan el grado $e$, cf. irl. ant. lige <*legiio-, nombre verbal de laigim 'yacer', o, precisamente, irl. ant. rige < * reg(i)iā- 'extensión, rección, acción de dirigir'; entonces iroreKiios quizá sea un bahuvrīhi, lo que parece encajar mejor con un antropónimo.

ción. Además de $\operatorname{IRRICO}(n)$, cf. irulases (var. lect. iTeulases) en K.18.3: ¿<*irr $(o)-u^{\circ}$ ? Habría que admitir que, como en galo (v. K. H. Schmidt, 1957, pp. 91-92), una vocal final del primer miembro de compuesto se elide ante otra.

${ }^{64}$ Cf. J. Untermann, MLH IV, p. 426, nota 40; más bibliografía sobre iroreKiios en D. Wodtko, $M L H \mathrm{~V}$, s.v. 
25. Si retomamos ahora las posibles interpretaciones que hemos ido acumulando para el análisis sintáctico de esta inscripción, de apariencia "inofensiva" - conocemos su función como documento de hospitalidad, poseemos diversos modelos latinos e indígenas con los que cotejarla, al menos aparece un nombre propio ...-, veremos que después de este minucioso tanteo de posibilidades etimológicas, en realidad hemos avanzado poco: las ambigüedades de la inscripción impiden encuadrarla satisfactoriamente dentro de los modelos conocidos. La hipótesis más verosímil es que K.14.1, dado el gran número de nominativos singulares implicados, sea una tésera bilateral, donde ambas partes se expresan en nominativo y en asíndeton, aunque no haya más paralelo que K.15.1. Nemaios es claramente un NP, y en el caso de iroreKiios, su conexión con el repertorio onomástico (§ 24) es más verosímil que construir un apelativo sin paralelos en la epigrafía hispano-céltica. Más difícil es determinar cual es la función de moniTuuKoos. El epíteto de las Matres Monitucinae ni excluye que sea un apelativo, ni que sea un étnico: ambas posibilidades quedan abiertas. Pero en ningún caso se espera que una epiclesis teonímica derive de un antropónimo, así que habrá que rechazar la asociación de moniTuuKoos con la base onomástica Con- \pm tuc(c)-, al menos como elemento serial - pero el apelativo *tuk(o)- postulado en $\S 11$ podría aparecer independientemente como base onomástica y como segundo miembro de un compuesto -. Si es un étnico, como es lo lógico en un documento de estas características, la posibilidad de que esté relacionado con *mono- 'monte', aunque verosímil, no es concluyente ( $\S 9-10)$. Si es un apelativo, con el significado etimológico 'perteneciente a la descendencia (*tuk-o-) bajo protección ( $\left.{ }^{\prime m o n i}\right)$ ' o bien, 'protegido, bajo tutela (*monitu-ko-)' obtenemos una etimología formal correcta, pero sin paralelo alguno en los documentos de hospitalidad celtibéricos. No obstante, hay que tener presentes ciertas téseras latinas: cuando el pacto se establece entre una comunidad y un individuo, la hospitalidad suele incluir a sus libertos y descendientes; así, en la de Herrera de Pisuerga, donde la ciuitas Maggauiensis otorga la ciudadanía honoraria a Ampáramos y a sus ... libertos posterosque, o en la de Paredes de Nava (CIL II, 5763: ... Licirni Intercatiensis tesseram hospitalem fecit cum ciuitate Palantina sibi et filiis suis posterisque ...). ¿Habría que entender que en K.14.1 se confirma o renueva un pacto entre IroreKiios y su "descendencia tutelada" y nemaios? Dado que no hay coordinación, esto es **iroreKiios moniTuuKoos-Kue, cf. KenTis-Kue "e hijo(s)" en K.1.3 passim, habría que pasar por admitir que 
iroreKiios sea un adjetivo en -iio- basado sobre un antropónimo **ir(r)orĕg-(o)- o **ir(r)orẹko-(esto es, "la descendencia tutelada de iroreK(o)-, la descendencia *ir(r)oregia"); esa formación antroponímica en -iió- tendría al menos un paralelo, el MVNERIGIO $(n)$ de Soria (citado en $\S 8$ ), si efectivamente este último es un NF como supone $\mathrm{M}^{\mathrm{a}}$ L. Albertos, 1975, p. $14^{65}$. Y sólo se podría explicar la posición sintáctica del adjetivo antroponímico, ante moniTuиKoos, debido a lo específico de ese término, sin paralelos. ¿O es que moniTuиKoos es un adjetivo concertado con nemaios, y el documento se establece entre iroreKiios y su "descendiente tutelado" nemaios por un lado - en asíndeton -, y el o los aleTuures, al reverso de la tésera, por el otro? La falta de conjunciones impide cualquier análisis sintáctico definitivo: por la tipología del documento, la interpretación de moniTuuKoos como étnico sigue siendo más verosímil en definitiva (sobre todo, dada su relación con el epíteto de las Matres Monitucinae) que la admisión de un apelativo, por vistosa o verosímil que sea su etimología. Tampoco es posible dilucidar de modo definitivo el valor y posición sintáctica de aleTuures: hay que forzar bastante las cosas ( $\S 21-23)$ para leer un nominativo singular *[alletorēes], homófono de un presunto $\dagger$ Alle $<t>$ orix, antropónimo, o, más aún, identificarlo con los $\alpha \lambda \lambda$ ó$_{\tau} \rho \gamma \varepsilon \varsigma$ de Estrabón, que sería la única baza para ver en aleTuures un étnico, ya que no presenta sufijo alguno (en -ko-, en $\bar{u} n$-, siquiera en -io-) que lo caracterice como tal. En definitiva, las opciones son: o bien aceptar con todo un NP *[alleto-rēe $\chi s]$ (¿equivalente al NP galo $\uparrow$ Alle<t>orix?), o más bien *[ad-lextu-rē $x s]$ como único ejemplo de NP en *-réxs del celtibérico, o bien, pese a la falta de buenos paralelos para los nombres de agente en *-tor- (§ 17-19), explicar aleTuures como nominativo plural de un $*$ al $(l) e(\chi)$-tūr-, referido a iroreKiios el *monitucense y a nemaios. Siguen en pie las palabras que cierran el comentario de Lejeune (1955, p. 84) a esta inscripción: «bien des questions, on le voit, attendant encore une réponse».

65 La inscripción es fragmentaria, Albertos, 1.c., lee LOVGVS A[...F. M]VNERIGIO( $n$ ). Parece más plausible una derivación *[M] unero- $+*$-iko- $+*$-iio- (paralela a $* *$ irroro $\rightarrow * *$ irror$\left.i k o-\left(>*_{-} e k o-\right)+*_{\text {-iijo-}}\right)$ que un compuesto *(M)une-rigg-io-, (ien contraste con el vocalismo de $\operatorname{ir}(r) o-r \bar{e} g-(o-) !)$, como supuso Albertos, 1966, p. 280. Aunque se podría sortear el problema de la $* \bar{e}\left(<-r e K->=* \bar{e} g\right.$, forma antigua vs. ${ }^{*} r \bar{g} g$, en epigrafía latina, reciente), un primer miembro $\dagger[m]$ une- tampoco resulta transparente (¿deformación de moni-?). 


\section{REFERENCIAS BIBLIOGRÁFICAS}

ACTAS I = Actas del I Coloquio sobre Lenguas y Culturas Prerromanas de la Península Ibérica, ed. F. Jordá, J. De Hoz y L. Michelena, Salamanca.

ACTAS II = Actas del II Coloquio sobre Lenguas y Culturas Prerromanas de la Peninsula Ibérica (Tübingen, 1976), Salamanca.

ACTAS III = Actas del III Coloquio sobre Lenguas y Culturas Paleohispánicas (Lisboa, 1980), ed. J. De Hoz, Salamanca.

ACTAS IV = Studia Palaeohispanica. Actas del IV Coloquio sobre Lenguas y Culturas Paleohispánicas (Vitoria/Gasteiz, 1985), eds. J. Gorrochategui, J. L. Melena y J. Santos, Vitoria.

ACTAS VI = La Hispania prerromana (Actas del VI coloquio sobre lenguas y culturas prerromanas, Coimbra 1994), Salamanca/Coimbra.

ACTAS VII = Pueblos, lengus y escrituras en la Hispania Prerromana (Actas del VII Coloquio sobre lenguas y culturas paleohispánicas, Zaragoza 1997, eds. F. Villar y F. Beltrán, Zaragoza-Salamanca.

ACTAS VIII = Religión, lengua y cultura prerromanas de Hispania. Actas del VIII Coloquio sobre lenguas y culturas prerromanas, Salamanca 1999, eds. F. Villar y Ma P. Fernández, Salamanca.

ALBERTOS, Ma Lourdes, 1966, La onomástica personal primitiva de Hispania. Tarraconense y Bética, Salamanca, CSIC

- 1975, «Organizaciones suprafamiliares en la Hispania antigua», BSEAA 40-41, pp. 5-66.

- 1979, «La onomástica de Celtiberia», Actas II, pp. 131-167.

- 1985, «La onomástica personal indígena del noroeste peninsular (astures y galaicos)», Actas III, pp. 256-310.

- 1987, «La onomástica personal indígena de la región septentrional», Actas IV, Vitoria, pp. 155-194.

BELTRÁN LLORIS, Francisco, 2001, «La hospitalidad celtibérica: una aproximación desde la epigrafía latina», Palaeohispanica 1, pp. 35-62.

BILLY, P.-H., 1993, Thesaurus Linguae Gallicae, Hildesheim-Zürich-New York.

Búa CARBAllo. C., 1999, «Hipótesis para algunas inscripciones rupestres del Occidente peninsular», Actas VII, pp. 309-327.

CAPAlvo, Álvaro, 1996, Celtiberia, Zaragoza.

CARNOY, Albert Joseph, 1906, Le Latin d'Espagne d'après les inscriptions, Bruselas (reimpresión: Hildesheim, 1971)

Castellano, Ma A. y Gimeno, H., 1999, «Tres documentos de hospitium inéditos», Actas VII, pp. 359374.

De Bernardo Stempel, P., 1996, «Die Stummvokale: eine Bilanz für das Keltiberische», Die größeren altkeltischen Sprachdenkmäler, eds. W. Meid y P. Anreiter, Innsbruck, pp. 212-256.

- 1999, Nominal Wortbildung des älteren Irischen, Tubinga.

De Hoz Bravo, J., 1986, «La epigrafía celtibérica», Actas de la Reunión sobre Epigrafía Hispánica de época romano-republicana, Zaragoza, 41-102.

- 1996, «IX. Aproximaciones a la interpretación del bronce», El tercer bronce de Botorrita (Contrebia Belaisca), eds. F. Beltrán, J. de Hoz y J. Untermann, Zaragoza, pp. 197-205.

- 1999, «Los metales inscritos en el mundo griego y periférico y los documentos celtibéricos en bronce», Actas VII, pp. 433-470.

De Hoz, J. - Michelena, L., 1974, La inscripción celtibérica de Botorrita, Salamanca.

Delamarre, Xavier, 2001, Dictionnaire de la langue Gauloise, París.

DiEgo SANTOS, F., 1985, Epigrafia romana de Asturias, Oviedo. 
ESKA, Joseph, 1989, Towards an interpretation of the Hispano-Celtic inscription of Botorrita, Innsbruck.

Evans, D. Ellis, 1967, Gaulish Personal Names, Oxford.

GÓMEZ-PantojA, J., 1999, «Las Madres de Clunia», Actas VII, pp. 421-431.

GORROCHATEGUI, Joaquín, 1990, «Consideraciones sobre la fórmula onomástica y la expresión de origen en algunos textos celtibéricos menores», Studia Indogermanica et Palaeohispanica in honorem A. Tovar et L. Michelena, ed. F. Villar, Salamanca, pp. 291-312.

HAMP. ERIC P., 1989, «Celtiberian ComPalCes», ZcPh 43, pp. 190-191

HOLDER I-III = HOLDER, Alfred, 1896, Altkeltischer Sprachschatz, Leipzig (reimpr. Graz, 1961).

LAMBERT, P.-Y., 1994, La Langue Gauloise, Paris.

LEJEUnE, M., 1955, Celtiberica, Salamanca.

$L I V_{2}=$ H. Rix (dir.), 2001, Lexikon der Indogermanischen Verben. Die Würzeln und ihre Primärstammbildungen, Wiesbaden ( $2^{\mathrm{a}}$ edición)

MARICHAL, R., 1988, Les Graffites de La Graufesenque, Paris, CNRS.

MCCONE, K., 1995, «Oir. senchae, senchaid and preliminaries on agent noun formation in Celtic», Ériu 46, pp. 1-10.

- 1996, Towards a Relative Chronology of Ancient and Medieval Celtic Sound Change, Maynooth.

MCMANUS, Damian, 1991, A Guide to Ogam, Mainooth.

MAYRHOFER EWAIA = MAYRHOFER, Manfred, 1992-2001, Etymologisches Wörterbuch des Altindoarischen (I-III), Heidelberg.

MEID, W., 1989, Zur Lesung und Deutung gallischer Inschriften, Innsbruck [IBS-Vtr. 40]

- 1992, Gaulish Inscriptions, Budapest.

- 1993, Die erste Botorrita-Inschrift. Interpretation eines keltiberischen Sprachdenkmals, Innsbruck.

- 1996, Kleinere keltiberische Sprachdenkmäler, Innsbruck [IBS-Vtr. 64]

MENÉNDEZ PIDAL, R., 1940, Manual de gramática histórica española, Madrid.

$M L H=\mathrm{v}$. UNTERMANN, $M L H$ III-IV, WODKO, $M L H \mathrm{~V} / 1$.

PEDERSEN, Holger, 1909-1913, Vergleichende Grammatik der keltischen Sprachen, Gotinga.

POKORNY, Juluis, 1959, Indogermanisches etymologisches Wörterbuch, Bern - München.

PRÓSPER, Blanca Mª 2002, Lenguas y religiones prerromanas del Occidenta de la Península Ibérica, Salamanca.

REICHERT, H., 2001, «Linksrheinische Germanen», Reallexiokon der Germanischen Altertumskunde, vol. 18 (Landschaftsrecht-Loxstedt), pp. 483-494.

REMESAl RodRígueZ, J., 1999, «En torno a una nueva tésera de hospitalidad», Actas VII, pp. 595-603.

$R I G=$ M. Lejeune, P.- Me Duval, G. Pinault, J.-B. Colbert De Beaulieu y B. Fischer, 1985-1998, Recueil des inscriptions Gauloises, vols. I-V, París, CNRS.

Rivet, A.L.F y SMITH, CoLIN, 1979, The Place-Names of Roman Britain, Londres.

Rodríguez Adrados, Francisco, 2002, «Sobre Botorrita IV», EMERITA 70, pp. 1-8.

RUBIO ORECILlA, F. J., 1996, «Tensiones paradigmáticas en el verbo celtibérico: auðeti, auðares, auðanto y otras formas emparentadas», Kalathos 15, pp. 181-193.

— 1999-2000, «Aproximación lingüística al bronce de Torrijo (Teruel)», Veleia 16, pp. 137-157.

— 2001, «Las formaciones secundarias en -ko- del celtibérico», Actas VIII, pp. 581-594.

- 2003, «Kamasiosuei ikenionke setantunos y otras téseras», Palaeohispanica (en prensa).

Russell, P., 1990, Celtic Word-Formation: the Velar Suffixes, Dublín.

SCHMIDT, Karl Horst, 1957, «Die Komposition in gallischen Personennamen», ZcPh 26, pp. 33-301.

— 1985, «A contribution to the indentification of Lusitanian», Actas III, pp. 319-341. 
SCHulten, A., 1914, Numantia, 1. Die Keltiberer und ihre Kriege mit Rom, Múnich. SCHUlZE, Wilhelm, 1966, Zur Geschichte Lateinischer Eigennamen, Berlín.

SCHRIJVER, P., 1991, The reflexes of the Proto-Indo-European larygeals in Latin, Amsterdam.

UHLICH, Jürgen, 1989, «DOV(A)- and lenited - $B$ - in Ogam», Ériu 40, pp. 129-133.

UNTERMANN, Jürgen, 1985, «Los teónimos de la región lusitano-gallega como fuente de las lenguas indígenas», Actas III, pp. 343-363.

- 1990, «Comentarios sobre inscripciones celtibéricas menores», Studia Indogermanica et Palaeohispanica in honorem A. Tovar et L. Michelena, ed. F. Villar, Salamanca, pp. 351-374.

- 1995, «Epigrafía indígena y romanización en la Celtiberia», Roma y el nacimiento de la cultura epigráfica en Occidente, ed. F. Beltrán, Zaragoza, pp. 197-208.

- 1996, «VI. Onomástica», El tercer bronce de Botorrita (Contrebia Belaisca), eds. F. Beltrán, J. de Hoz y J. Untermann, Zaragoza, pp. 109-180.

UNTERMANn, MLH III = UNTERMANN , J., 1990, Monumenta Linguarum Hispanicarum III.1: Die Iberische Inschriften, Wiesbaden.

UnTERmANn, MLH IV = UnTERMANN , J.,1997, Monumenta Linguarum Hispanicarum IV: Die tartessischen, keltiberischen und lusitanischen Inschriften, Wiesbaden.

VENDRYES, Joseph, 1958, «Quelques cas d'étymologie croisée en celtique», ÉC 8, pp. 298-314.

VILLAR LIÉBANA, F., 1993-1995, «Un elemento de la religiosidad indoeuropea: Trebarune, Toudopalandaigae, Tebopala, Pales, Viśpálā», Kalathos 13-14, pp. 355-388.

- 1995, Estudios de celtibérico y de toponimia prerromana, Salamanca.

- 1997, «The Celtiberian Language», Zeitschrift für celtische Philologie 49-50, pp. 898-949.

- 1999, «La tésera de slania y los nombres de familia con determinante», Studia Celtica et Indogermanica (Fs. W. Meid), eds. P. Anreiter y E. Jerem, Budapest, pp. 531-537.

Villar LiÉBANA, F. y ARBoledAS, P., 1999, «Sabora y el tratamiento de la /s/ en celtibérico», Tñऽ $\varphi$ $\lambda \operatorname{í}_{\varsigma} \tau \alpha \dot{\delta} \varepsilon \delta \tilde{\omega} \rho \alpha$, Miscelánea léxica en memoria de Conchita Serrano, Madrid, CSIC, pp. 427-435.

ViLlar LiéBAnA, F. y JoRdÁn CólerA, C., 2001 a, Recensión de Untermann, MLH IV, Kratylos 46, pp. 166-181

— 2001 , «Comentario paleo-epigráfico»-«Comentario lingüístico: fonética, morfología, semántica», El IV Bronce de Botorrita (Cotrebia Belaisca): arqueología y lingüística, eds. F. Villar, Ma A. Díaz, M. Medrano, C. Jordán, Salamanca, pp. 71-131.

Villar LiÉBAnA, F. y UnTermanN , J., 1999, «Las “téseras” de Gadir y Tarvodurum», Actas VII, pp. 719-731.

WoDTKO, MLH V/1 = WODTKO, D., 2000, Monumenta Linguarum Hispanicarum V.1: Wörterbuch der keltiberischen Inschriften, Wiesbaden.

ZIEGLER, Sabine, 1994, Die Sprache der altirischen Ogam-Inschriften, Gotinga. 